ISSN: 0514-7336 — ISSN electrónico: 2386-3943

DOI: https://doi.org/10.14201/zephyrus2020866786

\title{
EL PRESTIGIO DE LOS OBJETOS: MANGOS DE MARFIL EN EL MUNDO IBÉRICO
}

\section{The prestige of the objects: Ivory handles in the Iberian world}

\author{
Consuelo Mata Parreño*, Lucía Soria Combadiera**, Marta Blasco Martín*, Gianni Gallello*, \\ Maria Carme Belarte Franco*** y Agustín Pastor García****
}

* Dpto. de Prehistoria, Arqueología e Historia Antigua. Facultad de Geografía e Historia. Univ. de València. Avda. BlascoIbáñez,28.46010Valencia.Correo-e: consuelo.mata@uv.es; marta.blasco@uv.es; gianni.gallello@uv.es.ID ORCID: https://orcid.org/0000-0002-4260-4748; https://orcid.org/0000-0002-5360-8701; https://orcid.org/00000003-3641-8815

** Dpto. de Historia, Área de Prehistoria. Facultad de Humanidades. Univ. de Castilla-La Mancha. Campus Universitario, s/n.02071 Albacete.Correo-e: lucia.soria@uclm.es. ID ORCID: https://orcid.org/0000-0003-31586377

*** Institució Catalana de Recerca $i$ Estudis Avançats (ICREA). Passeig Lluís Companys, 23. 08010 Barcelona-Institut Català d'Arqueologia Clàssica (ICAC). Pl. del Rovellat, s/n. 43003 Tarragona. Correo-e: cbelarte@icac.cat.ID ORCID: https://orcid.org/0000-0002-2293-0482

**** Dpto. de Quimica Analitica. Facultad de Quimica. Univ. de Valencia. C/ Dr. Moliner, 50. 46100 Burjassot (Valencia).Correo-e: agustin.pastor@uv.es. ID ORCID: https://orcid.org/0000-0001-9454-1999

Recepción: 08/07/20; Revisión: 10/09/2020; Aceptación: 2/11/2020

Resumen: El estudio se centra en una serie de mangos de marfil de características morfotécnicas similares, recuperados en espacios de hábitat y funerarios ibéricos y datados entre el s. Iv y el s. II a. C. Se trata de objetos de prestigio al alcance de una élite aristocrática, que han sido elaborados con materias primas exóticas (marfil) y técnicas decorativas inusuales que indican una especialización. A través de análisis de composición por infrarrojo cercano por Transformada de Fourier (FT-NIR) y de fluorescencia de rayos X (pXRF) se ha podido documentar la presencia de incrustaciones de ámbar adheridas a la superficie de los mangos mediante el uso del estaño como soldadura blanda y el empleo de apliques metálicos de bronce y plata. Se debate sobre la procedencia de estas piezas y sobre el conocimiento técnico artesanal necesario para fabricarlas.

Palabras clave: aristocracia ibérica; artesanía; ámbar; metalurgia; plata; FT-NIR; PXRF.

AвSTRACT: This work focuses on ivory handles with similar morphotecnic characteristics recovered in both habitat and funerary spaces, dated between the $4^{\text {th }}$ and $2^{\text {nd }}$ century BC. These are prestigious objects only accessible to the aristocratic elite, and have been manufactured with exotic materials (ivory) and unusual decorative techniques that show a specialization Trough Fourier transform near-infrared (FT-NIR) and portable $\mathrm{X}$-ray fluorescence (PXRF) analysis, it has been possible to document amber inlays adhered to the surface of the handles by using tin as a soft solder. Likewise, some of these objects are decorated with bronze overlays and, exceptionally in one of those, the handle is covered on its sides with a silver sheet. The origin and necessary craft technical knowledge to make these objects is discussed.

Key words: Iberian aristocracy; craftwork; amber; metallurgy; silver; FT-NIR; pXRF. 


\section{Introducción ${ }^{1}$}

Hay objetos que, por sus características físicas, por la materia prima en la que están elaborados y/o por la decoración que presentan, en suma, por su valor artesanal, son considerados de prestigio y tienen una importante distinción económica e incluso estima social y personal.

La revisión de las industrias sobre materias duras animales de época ibérica nos muestra que los mangos son objetos habituales cuyo número solo es superado por los alfileres óseos ${ }^{2}$. Estas piezas enmangaban pequeñas cuchillas u hojas metálicas facilitando su uso, mejorando su rendimiento y protegiendo las manos de los usuarios. En el registro arqueológico es común encontrar ambas partes por separado, lo que dificulta la asociación de un mango con su hoja. No obstante, algunos conservan toda o parte de la hoja incrustada, así como restos de óxido.

La mayoría de los mangos conocidos están elaborados sobre diáfisis de huesos largos de meso- y macromamíferos o sobre candiles y partes mesiales aserradas de cuernas de ciervo. Hemos documentado más de 50 piezas entre las que destacan las de Alto Chacón (Teruel) (Atrián, 1976: 35 y 76), El Palomar (Oliete, Teruel) (Blasco, 2018: 143 y fig. 4), Saus (Saus-Camallera-Llampaies, Girona) (Casas y Soler, 2012: 150-151), Mas Castellar (Pontós, Girona) (Pons, 2002: 408-409) y el Puig de Sant Andreu (Ullastret, Girona) (Martín et al., 2004: fig. 11). También fueron realizados en madera, siendo seguramente una de las materias primas más utilizadas, pero cuya conservación e identificación resultan problemáticas (Badal et al., 2017). Apenas tenemos catalogados una decena, pertenecientes a

1 Los firmantes de este artículo forman parte de los siguientes grupos de investigación: Grup de Recerca en Arqueologia del Mediterrani-Gram; Grupo Prehistòria del Mediterani Occidental-premedoc; Grupo de Investigación Arqueología y Patrimonio-ARQPAT; Soluciones e Innovación en Química Analítica-solinquiana.

2 Blasco Martín, M. (2020): Piezas de hueso, asta, cuerno y marfil en época ibérica. De su elaboración a su interpretación. Tesis doctoral inédita presentada en 2020 en la Univ. de Valencia. herramientas en general. En este trabajo nos centramos en un conjunto de once mangos (Fig. 1) recuperados en nueve yacimientos (Fig. 2) elaborados sobre una materia prima alóctona a la Península Ibérica, el marfil. Todos tienen características morfotécnicas similares pudiendo describirse como piezas laminares con el talón redondeado, de mayor anchura que la espiga, y un pequeño saliente actuando de defensa o guarda de la mano. La hoja se insertaba en el extremo distal que se sujetaba con unas virolas y remaches de metal.

Tipológica y tecnológicamente todos son mangos con talón, pero pueden individualizarse y compararse por su decoración o por su ausencia (Figs. 1 y 3). El Tipo 1 está constituido por cinco mangos publicados previamente (Blasco et al., 2019): El Cigarralejo (Mula, Murcia) (ec); Coimbra del Barranco Ancho (Jumilla, Murcia), uno recuperado en la Necrópolis del Poblado y otro en el asentamiento (CBA1 y 2); Turó del Montgrós (El Brull, Barcelona) (TM); y uno de los ejemplares de La Serreta (Alcoi-Cocentaina-Penàguila, Alicante) (Ls1). Todos ellos son piezas excepcionales al contar con decoración taraceada, por ambas caras, con rebajos de formas variadas -fundamentalmente lanceoladas, pero también circulares, rectangulares, escutiformes y romboidales- en la espiga, el lomo y el talón. En los rebajos lanceolados de TM y LS1 hay evidencias de una sustancia grisácea que los cubre, que también se encuentra en torno a las incrustaciones conservadas. A estos ejemplares añadimos un mango de El Coll del Moro (Gandesa, Tarragona) (Figs. 1 y 3 , $\mathrm{CM}$ ), con rebajos similares a los citados, aunque no conserva las incrustaciones. El Tipo 2 está integrado por tres piezas (Figs. 1 y 3, SAC, CB, PLL; Fig. 2) con decoración metálica, especialmente un disco aplicado en el talón y un revestimiento para PLL. Y, finalmente, el Tipo 3 lo componen dos carentes de decoración (Figs. 1 y 3, EM y Ls2).

\section{Los mangos: lugares de hallazgo y contextos}

Como hemos apuntado, estos mangos presentan particularidades morfológicas, decorativas, de contexto y de distribución geográfica y 

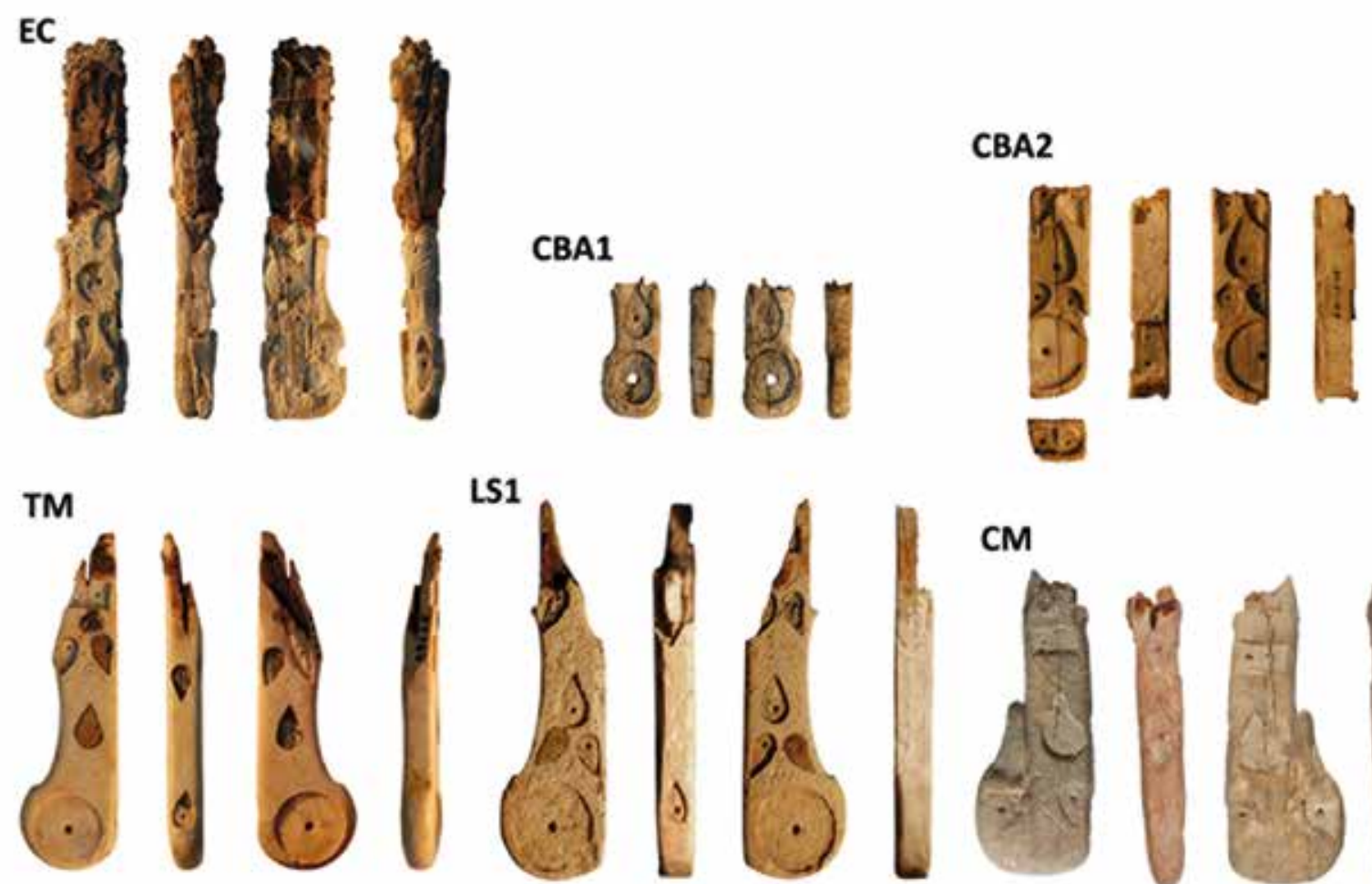

LS1

\section{SAC}
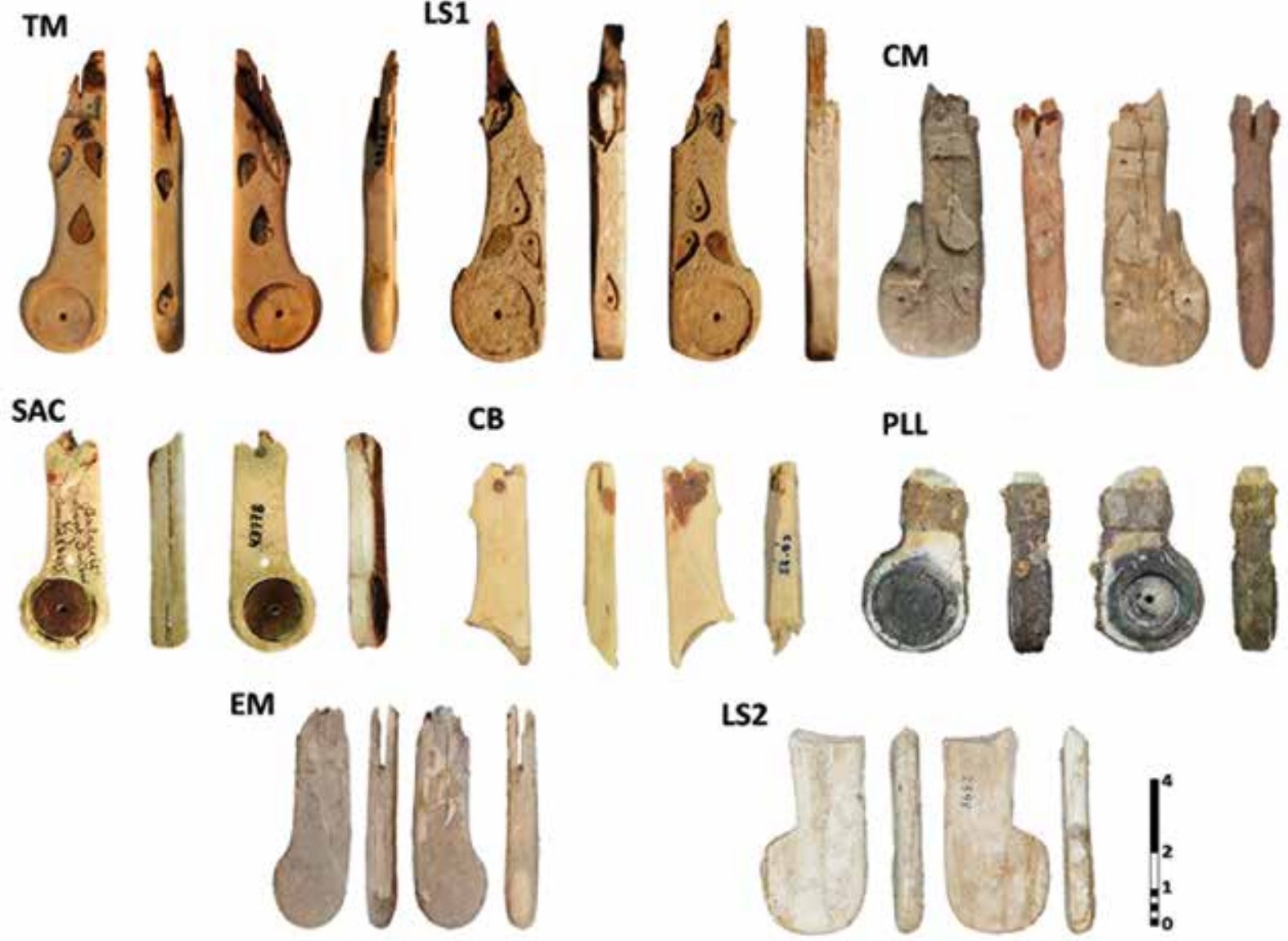

PLL

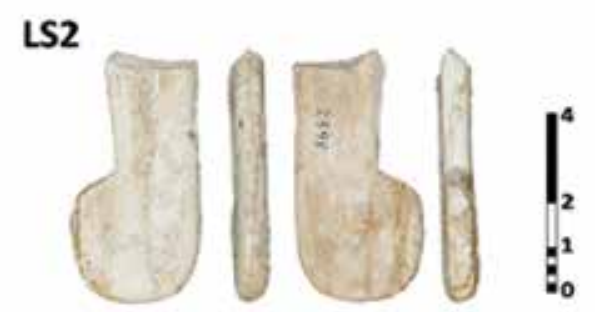

Fig. 1. Mangos de marfil estudiados.

cronológica que permiten abordar aspectos relacionados con su producción y con los gustos estilísticos propios de sus usuarios/as. Presentamos, siguiendo un orden cronológico, los yacimientos donde se han documentado y sus descripciones (Figs. 1-3).

\subsection{El Cigarralejo (Mula, Murcia)}

Este complejo arqueológico está integrado por un poblado, su necrópolis y un santuario. En los años cuarenta del s. xx E. Cuadrado inició los trabajos arqueológicos, sobre todo en la necrópolis, 
datada entre finales del s. v y el s. I a. C. (Cuadrado, 1987; De Prada y Cuadrado, 2019).

De la Tumba 294 procede un mango descrito como de hueso (Cuadrado, 1987: 506) (Figs. 1-3, Ec), cuya revisión en el Museo de Arte Ibérico El Cigarralejo $-\mathrm{n} .^{\mathrm{o}}$ inv. 3030- puso de manifiesto que se trata de marfil. Conserva parte de la espiga, el talón y un fragmento de la hoja de hierro. Presenta rebajos lanceolados y circulares de distinto tamaño en ambas caras y un pequeño rebajo romboidal en el lomo. No se conservan las incrustaciones y está bastante deteriorado, probablemente, por haber estado en contacto con el fuego. La tumba se ha datado entre el 350-325 a. C.

\subsection{El Molar (San Fulgencio, Alicante)}

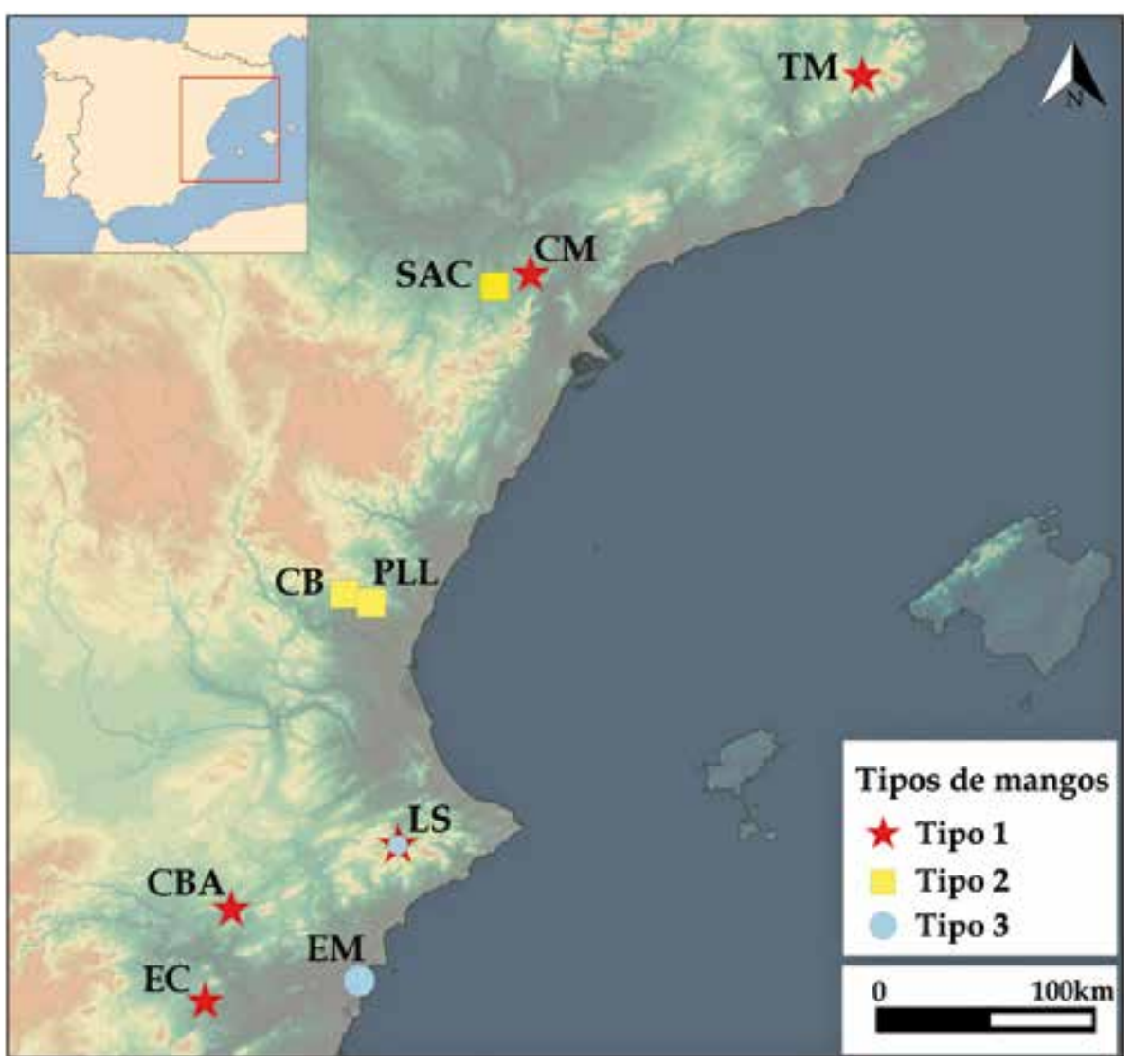

Fig. 2. Yacimientos: $T M=$ Turó del Montgrós (El Brull, Barcelona); $C M=$ Coll del Moro (Gandesa, Tarragona); SAC = Sant Antoni/San Antonio (Calaceit/Calaceite, Teruel); $C B=E l$ Castellet de Bernabé (Llíria, València); PLL = El Puntal dels Llops (Olocau, València); $L S=$ La Serreta (Alcoi-Cocentaina-Penàguila, Alicante); $C B A=$ Coimbra del Barranco Ancho (Jumilla, Murcia); $E M=$ El Molar (San Fulgencio, Alicante); $E C=E l$ Cigarralejo (Mula, Murcia). Tipos: 1) mangos taraceados con incrustaciones de ámbar (conservadas o no); 2) mangos con decoración metálica; 3) mangos sin decoración.

Necrópolis excavada a finales de los años 20 del s. xx por J. Lafuente y J. J. Senent (Senent, 1930; Monraval, 1992; Peña, 2003). En 1982 se llevó a cabo una intervención de urgencia en la que se localizó un silicernium, de donde procede el mango analizado (Monraval y López Piñol, 1984: fig. 8, 9) (Figs. 1-3, EM). Fue publicado como de hueso, pero su revisión en el MARQ, donde está depositado - n. ${ }^{\circ}$ inv. cs 370-, nos permite asegurar que se trata de un mango ebúrneo. Conserva el talón redondeado, parte de la espiga y evidencias de la abertura longitudinal donde iría la parte activa; sin embargo, no presenta indicio alguno de restos metálicos de la hoja o de los clavos que podrían fijarla; y carece de decoración.

\subsection{Coimbra Barranco Ancho (Jumilla, Murcia)}

Conjunto arqueológico formado por el poblado, un santuario y tres necrópolis. Las primeras intervenciones en 1956 fueron dirigidas por J. Molina. Las excavaciones continúan desde 1977 con algunos paréntesis ${ }^{3}$ (García Cano, 1997; García Cano et

3 https:/www.um.es/coimbra/ (acceso 03/03/2020). 


\begin{tabular}{|c|c|c|c|c|c|c|c|}
\hline ID & YACIMIENTO & CONTEXTO & CRONOLOGÍA & DECORACIÓN & $\begin{array}{l}\text { LONGITUD } \\
(\mathrm{cm})\end{array}$ & ANCHURA $(\mathrm{cm})$ & $\begin{array}{l}\text { GROSOR } \\
(\mathrm{cm})\end{array}$ \\
\hline EC & El Cigarralejo & funerario & s. IV a. C. & Tipo 1 & 7,80 & 1,90 máx./1,20 mín. & 0,85 \\
\hline EM & El Molar & funerario & 1. ${ }^{\text {er } 1 / 4} \mathrm{~s}$. IV a. C. & Tipo 3 & 5,50 & 1,85 máx./1,45 mín. & 0,80 \\
\hline CBA1 & $\begin{array}{l}\text { Coimbra del } \\
\text { Barranco Ancho }\end{array}$ & funerario & s. IV- s. III a. C. & Tipo 1 & 2,10 (cons.) & 1,10 máx./0,83 mín. & 0,53 \\
\hline СВА 2 & $\begin{array}{l}\text { Coimbra del } \\
\text { Barranco Ancho }\end{array}$ & hábitat & s. IV-s. III a. C. & Tipo 1 & 4,60 (cons.) & 1,30 (cons.) & 0,80 \\
\hline LS1 & La Serreta & hábitat & s. III- s. II a. C. & Tipo 1 & 8 & 2,40 máx./1,50 mín. & 0,90 \\
\hline LS2 & La Serreta & hábitat & s. III- s. II a. C. & Tipo 3 & 5,30 & 2,70 máx./1,90 mín. & 0,70 \\
\hline $\mathrm{TM}$ & Turó del Montgrós & hábitat & s. III a. C. & Tipo 1 & 7,45 & 2,20 máx./1,30 mín. & 0,80 \\
\hline PLL & Puntal del Llops & hábitat & s. III a. C. & Tipo 2 & 4,50 (cons.) & 2,70 & 0,70 \\
\hline Св & Castellet de Bernabé & hábitat & $\begin{array}{l}\text { s. III-inicios del } \\
\text { s. II a. C. }\end{array}$ & Tipo 2 & 4,80 & 1,50 & 0,80 \\
\hline SAC & San Antonio & hábitat & 220-180 a. C. & Tipo 2 & 5,50 & 2,10 & 0,80 \\
\hline $\mathrm{CM}$ & Coll del Moro & hábitat & s. II a. C. & $\begin{array}{c}\text { Tipo } 1+ \\
\text { zoomorfo }\end{array}$ & 6,40 & 2,30 máx./1,30 mín. & 0,90 \\
\hline
\end{tabular}

Fig. 3. Tabla descriptiva de los mangos de marfil con medidas expresadas en cm: Tipo 1) decoración taraceada con incrustaciones (ámbar); Tipo 2) decoración metálica con disco de bronce que en el caso de PLL cuenta además con revestimiento de plata; Tipo 3) sin decoración.

al., 2008; Gallardo et al., 2017). De este complejo proceden dos mangos de marfil, depositados en el Museo Arqueológico Municipal Jerónimo Molina, uno del asentamiento $-\mathrm{n} .^{\circ}$ excavación COI-J19- y otro de la necrópolis del Poblado $-n .^{\circ}$ inv. 11043- (Figs. 1-3). Este último - СBA1-conserva dos rebajos en ambas caras, uno lanceolado en la espiga y otro circular en el talón; en el lomo hay otro rectangular. Los rebajos circulares presentan una incisión alrededor de su circunferencia y un orificio central que perfora toda la lámina. Se localizó fuera de la Tumba в (García Cano, 1997: 255-256, fig. 162, 6, n. $\left.{ }^{0} 1104-3\right)$, con una cronología genérica de los ss. IV-III a. C.

El mango del asentamiento-СBA2- cuenta con la misma decoración por ambas caras: círculo con punto central en el talón y un rebajo lanceolado delimitado por la parte superior e inferior por otros cuatro, de la misma forma, pero de menor tamaño, dispuestos en parejas. En el lomo de la espiga presenta dos rebajos rectangulares perforados, uno de ellos incompleto, y en el lomo del talón, un rebajo escutiforme y otro rectangular incompleto, ambos también con orificio central. En los rebajos circulares, se aprecian las marcas dejadas por la herramienta empleada para extraer el marfil. Se desconoce el contexto de hallazgo, por lo que se data con la cronología general del poblado, entre los ss. IV-III a. C. (Page et al., 1987: 67).

\subsection{La Serreta (Alcoi-Cocentaina-Penàguila, Alicante)}

Asentamiento fortificado del que también se conoce un santuario y la necrópolis. La primera campaña de excavación, realizada por C. Visedo, data de 1917. Presenta una larga ocupación desde el s. VI al II a. C., aunque su máximo esplendor se dio entre el s. IV e inicios del II a. C. (Llobregat et al., 1992; Olcina et al., 1998).

La revisión de las piezas hechas sobre materias duras de origen animal ha permitido clasificar como marfil dos peines y dos mangos publicados como de hueso (Mata et al., 2017a: 148-149). La Serreta es uno de los lugares con más objetos de marfil identificados de época ibérica. Los dos mangos, depositados en el Museu Arqueològic Municipal Camil Visedo -Ls1, n. ${ }^{\circ}$ inv. 2096; Ls2, n. ${ }^{\circ}$ inv. 2598-, proceden del asentamiento (Figs. 1-3).

Uno de ellos - Ls1- conserva parte de la hoja de hierro (Grau, 1996: 113). Se localizó en un área doméstica del Sector F. Está decorado, por ambos lados, con nueve rebajos lanceolados, dos de los cuales conservan ámbar incrustado. Dos rebajos circulares 
se sitúan a ambos lados del talón y otro lanceolado está en el lomo. En uno de los lados se aprecia el rebajo rectangular para la virola que sujetaría la hoja de hierro. En casi todos los rebajos lanceolados y alrededor del ámbar incrustado se puede apreciar el estaño utilizado como adherente para fijarlo (Blasco-Martín et al., 2019).

El segundo mango carece de decoración y solo conserva el talón y el arranque de la espiga -LS2-. La forma del talón no resulta totalmente redondeada y no presenta evidencias de la apertura utilizada para encajar la hoja metálica ni de clavos u otros elementos de sujeción.

\subsection{Turó del Montgrós (El Brull, Barcelona)}

Asentamiento fortificado de 9 ha en el que se documentan una ocupación del Bronce Final, sin estructuras asociadas, y una muralla ibérica de los ss. v-IV a. C. Se han realizado trabajos de excavación y consolidación desde 1975 (López Múllor, 2011, con bibliografía anterior).

El mango se recuperó en los años 80 (Molist y Rovira, 1986-1989: 134, fig. 36, n. ${ }^{\circ}$ 55) y está depositado en la sede de Barcelona del Museu d'Arqueologia de Catalunya (n. ${ }^{\circ}$ inv. MAC BCN 29226). Se encontró sobre el pavimento de una de las casamatas de la primera mitad del s. III a. $\mathrm{C}^{4}$. La pieza conserva el talón y parte de la espiga; la parte distal está fragmentada. La espiga es recta y las dos caras del talón presentan un rebajo circular. Conserva tres rebajos lanceolados en ambas caras, un rebajo rectangular en una de ellas, y dos pequeños rebajos lanceolados en el lomo. En una de las caras conserva dos incrustaciones de ámbar fijadas con estaño (Blasco-Martín et al., 2019) (Figs. 1-3, тM).

\subsection{El Puntal dels Llops (Olocau, València)}

Fortín de la red defensiva del Tossal de Sant Miquel (Llíria, València), la antigua Edeta, totalmente

4 Los detalles sobre el contexto de la pieza han sido facilitados por N. Molist (MAC-Barcelona). excavado y publicado. Estuvo habitado desde el s. v a. C. hasta el primer cuarto del s. II a. C. (Bonet y Mata, 1981, 2002).

El mango se encontró en el dep. 4, interpretado como un espacio aristocrático (Fig. 1-3, PLL). Fue publicado como de hueso, pero su revisión en el Museu de Prehistòria de València, donde está depositado -n. ${ }^{\circ}$ inv. 56176-, ha permitido identificarlo como marfil (Bonet y Mata, 2002: 68, 162, fig. 70, 4127). Su cronología es la del momento de destrucción y abandono del lugar. Conserva el talón redondeado decorado con dos arandelas y dos placas circulares de metal incrustadas en ambas caras, una de ellas desprendida, una virola metálica y una lámina, también metálica, que rodea los laterales, que serviría tanto de decoración como de sistema de refuerzo por lo que pudo tratarse de una reparación de la pieza.

\subsection{El Castellet de Bernabé (Llíria, València)}

Granja fortificada perteneciente al territorio edetano, destruida y abandonada entre finales del s. III y el primer cuarto del II a. C., aunque tiene su origen en el s. v a. C. (Guérin, 2003).

El mango se encontró en un espacio abierto interpretado como una plaza (cata 4, pasillo este), entre abundante material cerámico y una reducida presencia de objetos de hierro y bronce, entre ellos una hoja incompleta de podón o cuchillo afalcatado que quizás podría relacionarse con este mango. Fue publicado como de hueso (Guérin, 2003: 85, fig. 124, 411 y 414), pero su revisión en el $\mathrm{Mu}$ seu de Prehistòria de València -n. ${ }^{\circ}$ inv. 64657- ha confirmado que se trata de marfil. Presenta el inicio del talón redondeado que contaría con un rebajo circular por ambas caras, lo que sugiere que llevaría inserta una placa circular de bronce similar a los mangos de Sant Antoni y el Puntal dels Llops (Figs. 1-3, Св, tipo 2). En la espiga se ha conservado una perforación circular de $0,15 \mathrm{~cm}$ de diámetro donde permanece inserto un clavo de hierro que fijaría la hoja del útil, parcialmente conservada (Fig. 4.a). 

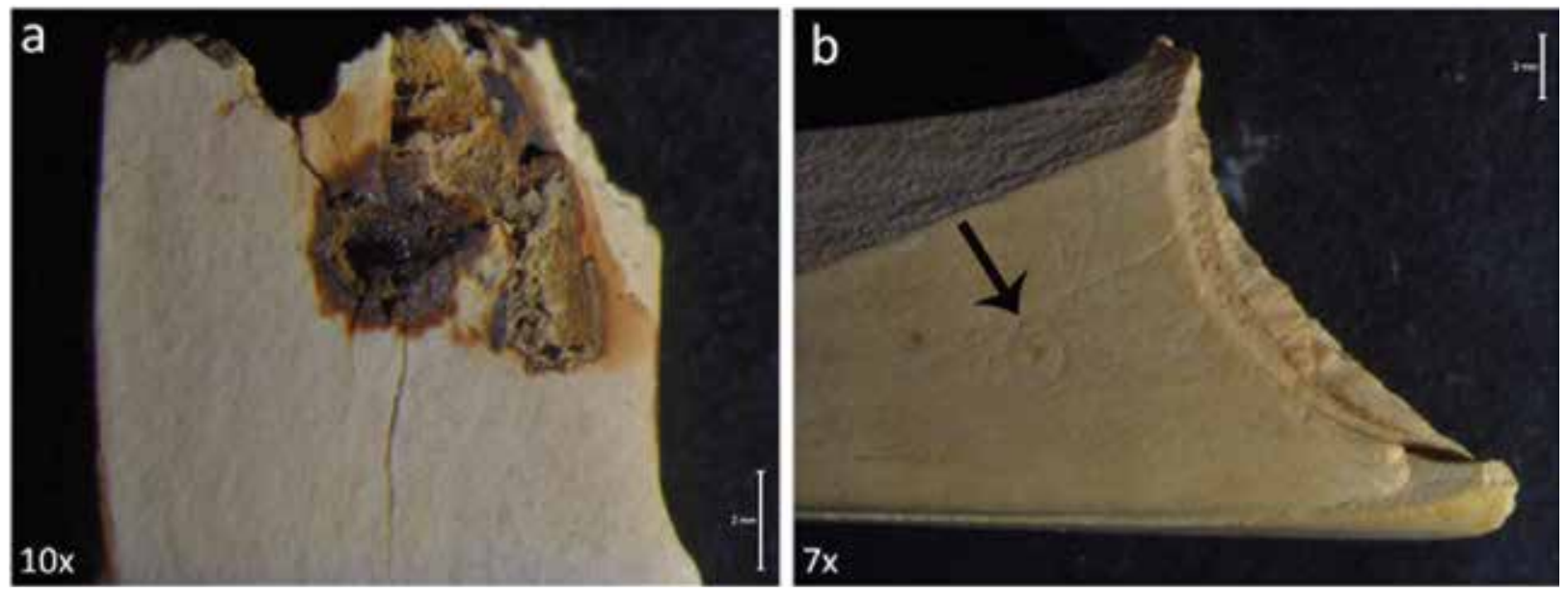

FIG. 4. Fotografias de detalle del mango СB tomadas con microscopio estereoscópico en el MUPREVA.

Resulta interesante la presencia de un pequeño círculo inciso con punto central en el extremo proximal del mango $-0,15 \mathrm{~cm}$ de diámetro-, junto al rebajo circular. Este motivo decorativo, apenas visible, se ha identificado mediante microscopía estereoscópica (Fig. 4.b).

\subsection{Sant Antoni/San Antonio (Calaceite, Teruel)}

Asentamiento ocupado entre mediados del s. v y finales del III a. C. Las primeras excavaciones estuvieron a cargo de J. Cabré entre 1902 y 1903, pero sería P. Bosch Gimpera quien realizaría la excavación completa del yacimiento, entre 1915 y 1922. F. Pallarés publicó los materiales (Pallarés, 1965) y E. Sanmartí las importaciones (Sanmartí-Grego, 1975). Una revisión reciente del conjunto de materiales -depositados en el MAC-Barcelona-, así como de las estructuras y fases del yacimiento, ha sido objeto de la tesis doctoral de R. Jornet (2017).

Durante los trabajos de Bosch Gimpera, se recuperó en el Dpto. c del Edificio 3 un mango incompleto de marfil, también publicado como de hueso (Figs. 1-3, sAC). El talón redondeado cuenta con dos placas circulares de bronce a ambos lados. La espiga conserva engastada parte de la hoja de hierro, fijada mediante un pequeño clavo metálico (Pallarés, 1965: 100; Jornet, 2017: 91, fig. 9.17.3).

\subsection{El Coll del Moro (Gandesa, Tarragona)}

Conjunto arqueológico formado por una necrópolis tumular del Bronce Final y Primer Hierro y un asentamiento fechable a partir del s. viI a. C. con una fase de ocupación tardo-republicana y otra alto-imperial. Excavado de forma discontinua desde 1971 (Rafel et al., 2015, con bibliografía anterior), desde 2014 se realizan intervenciones programadas en el hábitat (Jornet et al., 2016 y 2020).

El mango procede del núcleo de hábitat, concretamente del pavimento -UE 2039- del Sector 3 de la Zona 2, que forma parte de un gran edificio en torno a un espacio central abierto, construido en la fase tardo-republicana sobre un nivel de destrucción de c. 200 a. C. El abandono del sector 3 se ha datado a finales del s. II a. C. El mango conserva el talón y parte de la espiga; la parte distal está fragmentada (Figs. 1-3, сM). Además de los rebajos lanceolados y romboidales la pieza no cuenta con rebajo circular en el talón. Asimismo, presenta otra particularidad importante con respecto al resto: una serie de incisiones que permiten distinguir, en el extremo proximal de la pieza, la cabeza vuelta hacia 
atrás de un ánade, con los ojos indicados mediante un suave rebajo y una perforación central y el pico apoyado en la espiga. Presenta, por tanto, un talón decorado con un motivo zoomorfo.

\section{Análisis químicos}

Uno de los problemas que nos planteó el estudio de los mangos Ls1 y TM fue la caracterización de sus componentes decorativos. Los análisis de pXrF y FT-NIR permitieron identificar, por primera vez, el uso del estaño como adherente y el ámbar en la elaboración de esas piezas (Blasco-Martín et al., 2019). En este trabajo empleamos las mismas técnicas para analizar PLL, CM y SAC y determinar la presencia o no de estos materiales e identificar la naturaleza del refuerzo metálico del PLL. Los resultados han aportado valiosa información sobre los procesos productivos de estos mangos.

Los elementos mayoritarios se midieron con un espectrómetro portátil de fluorescencia de rayos $\mathrm{X}$-pXrF-. El modelo y las características son las mismas que las ya publicadas (Blasco-Martín et al., 2019). Las superficies de los mangos no han sido manipuladas antes de llevar a cabo las mediciones y los puntos de medida han sido seleccionados evitando, cuando ha sido posible, las zonas de mayor corrosión. El uso de la cámara integrada en el área de salida del disparo con video de circunscripción del punto de medida ha permitido seleccionar con precisión las áreas de medición. Para la obtención de los resultados, se utilizaron las aplicaciones Geochem-trace empleadas normalmente para medidas de matrices inorgánicas - determinando elementos y óxidos como $\mathrm{CaO}, \mathrm{P} 2 \mathrm{O} 5$ y $\mathrm{Sr}-$ y la modalidad Restricted Materials Alloys que se utiliza para medidas de metales y aleaciones - $\mathrm{Al}, \mathrm{Ti}, \mathrm{Fe}, \mathrm{Ni}, \mathrm{Cu}, \mathrm{As}$, $\mathrm{Ag}, \mathrm{Sn}$ y $\mathrm{Pb}-$.

Con el Infrarrojo cercano por Transformada de Fourier (FT-NIR) se midieron directamente diferentes puntos utilizando una sonda de fibra óptica para obtener espectros. Estos se obtuvieron en unidades Kubelka-Munk, en la región espectral de
14,000-4000 $\mathrm{cm}^{-1}$, utilizando una resolución de 4 $\mathrm{cm}^{-1}$ y acumulando 50 escaneos por espectro.

\subsection{PXRF}

\subsubsection{Mango de Sant Antoni-SAC-}

Este mango se midió mediante pXrF empleando las aplicaciones Geochem-trace y Restricted Materials Alloys (Fig. 5). Los resultados de Geochem-trace muestran niveles elevados de $\mathrm{CaO}$ en los puntos $17,19,20,21,24,27,28$ (13,46-28,87\%), correspondientes al marfil. Valores elevados de Sn se obtuvieron en los puntos 4, 5, 11 y 12 , que corresponden a la zona entre la placa metálica circular y el marfil (10,4-15,06\%) y áreas cercanas al aplique en los puntos $6(22,8 \%)$ y $13(16 \%)$. También con el método Alloys se aprecia que la composición de la placa decorativa contiene básicamente un $79-86 \%$ de cobre, un $10-13 \%$ de estaño y otros metales en menor porcentaje. Entre estos últimos debemos destacar los niveles reducidos en los apliques metálicos (puntos 1, 2, 8 y 9) de $\mathrm{Ag}(0,02 \%)$ y $\mathrm{Pb}$ (entre 1,05 y $2,87 \%$ ) porque constituyen un rasgo diferenciador con PLL (Fig. 7).

Los puntos 3 y 10 corresponden al remache y a los restos de la hoja de hierro y presentan una composición distinta a las placas metálicas, caracterizada por una ausencia y baja presencia de estaño. Estos resultados no permiten confirmar que el estaño se haya empleado para adherir la pieza de bronce al mango, al ser el estańo uno de los componentes principales del bronce.

\subsubsection{Mango de Coll del Moro - $\mathrm{CM}-$}

En esta pieza, en la que no hay restos de incrustaciones, los resultados revelan que los valores más elevados en los puntos analizados corresponden a $\mathrm{CaO}$ y $\mathrm{P} 2 \mathrm{O} 5$, tal como era de esperar al tratarse de elementos mayoritarios en la composición del marfil (Ca5(PO4)3(OH)) (Fig. 6). 

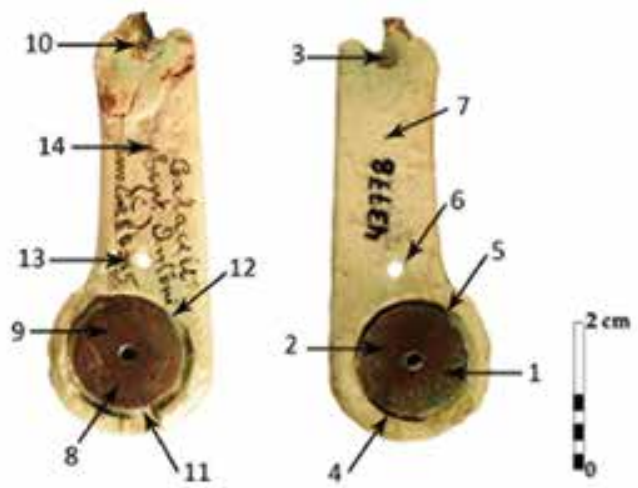

Método Alloys

\begin{tabular}{|c|c|c|c|c|c|c|c|c|c|}
\hline ID & Al & Ti & Fe & Ni & Cu & As & Ag & Sn & Pb \\
\hline SAC1 & 4,3 & & 0,30 & 0,06 & 82,5 & 0,27 & 0,02 & 10,4 & 1,90 \\
\hline SAC2 & 3,5 & 0,03 & 0,45 & 0,07 & 79,7 & 0,37 & 0,02 & 12,6 & 2,87 \\
\hline SAC3 & 15,7 & 0,11 & 3,05 & 0,18 & 55,6 & 0,13 & 0,05 & & 0,96 \\
\hline SAC4 & $<$ LOD & 0,02 & 0,36 & 0,10 & 86,5 & 0,35 & $<$ LOD & 10,4 & 1,84 \\
\hline SAC5 & $<$ LOD & 0,03 & 0,90 & 0,19 & 79,1 & 0,39 & $<$ LOD & 15,6 & 2,96 \\
\hline SAC6 & $<$ LOD & 0,30 & 8,18 & 2,25 & 51,0 & 1,28 & $<$ LOD & 22,8 & 4,68 \\
\hline SAC7 & 28,1 & 0,25 & 5,01 & 1,73 & 14,4 & 0,66 & $<$ LOD & $<$ LOD & 2,98 \\
\hline SAC8 & 4,7 & $<$ LOD & 0,26 & 0,04 & 82,3 & 0,54 & 0,02 & 10,0 & 1,91 \\
\hline SAC9 & $<$ LOD & $<$ LOD & 0,33 & 0,06 & 83,6 & 0,53 & 0,02 & 10,8 & 1,05 \\
\hline SAC10 & $<$ LOD & 0,12 & 17,47 & 0,13 & 59,7 & 0,23 & 0,08 & 0,19 & 0,98 \\
\hline SAC11 & $<$ LOD & $<$ LOD & 0,30 & 0,07 & 86,5 & 0,45 & $<$ LOD & 10,5 & 1,93 \\
\hline SAC12 & $<$ LOD & 0,03 & 0,62 & 0,16 & 83,0 & 0,28 & $<$ LOD & 13,0 & 2,37 \\
\hline SAC13 & $<$ LOD & 0,78 & 11,98 & 3,17 & 29,6 & $<$ LOD & $<$ LOD & 16,0 & $<$ LOD \\
\hline SAC14 & $<$ LOD & 0,90 & $<$ LOD & 2,28 & 5,53 & 0,89 & $<$ LOD & 3,29 & $<$ LOD \\
\hline
\end{tabular}
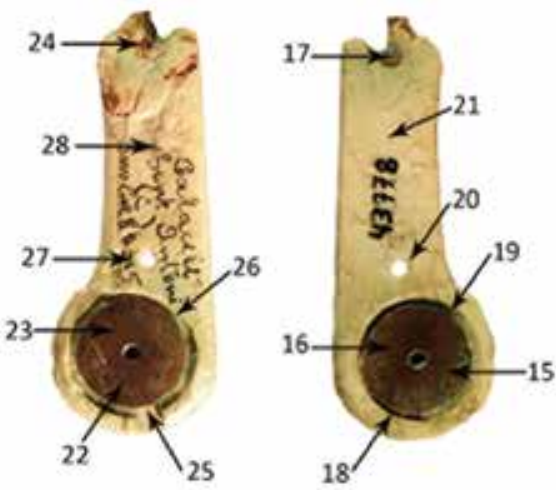

Método Geochem

\begin{tabular}{|l|c|c|c|}
\hline ID & P2O5 & CaO & Sr \\
\hline SAC15 & 0,65 & 1,81 & 0,08 \\
\hline SAC16 & $<$ LOD & 1,68 & 0,11 \\
\hline SAC17 & 20,6 & 28,60 & 0,15 \\
\hline SAC18 & 4,83 & 7,61 & 0,12 \\
\hline SAC19 & 11,0 & 16,41 & 0,13 \\
\hline SAC20 & 16,2 & 29,58 & 0,11 \\
\hline SAC21 & 14,3 & 28,77 & 0,10 \\
\hline SAC22 & $<$ LOD & 1,33 & 0,07 \\
\hline SAC23 & $<$ LOD & 0,67 & $<$ LOD \\
\hline SAC24 & 9,12 & 13,46 & 0,14 \\
\hline SAC25 & 3,66 & 9,41 & 0,12 \\
\hline SAC26 & 4,77 & 8,22 & $\mathbf{0 , 1 2}$ \\
\hline SAC27 & 11,5 & 24,79 & 0,10 \\
\hline SAC28 & 17,7 & 28,87 & 0,12 \\
\hline
\end{tabular}

FIG. 5. Puntos de análisis y resultados obtenidos mediante análisis PXRF a través de las aplicaciones Alloys y Geochem del mango SAC.
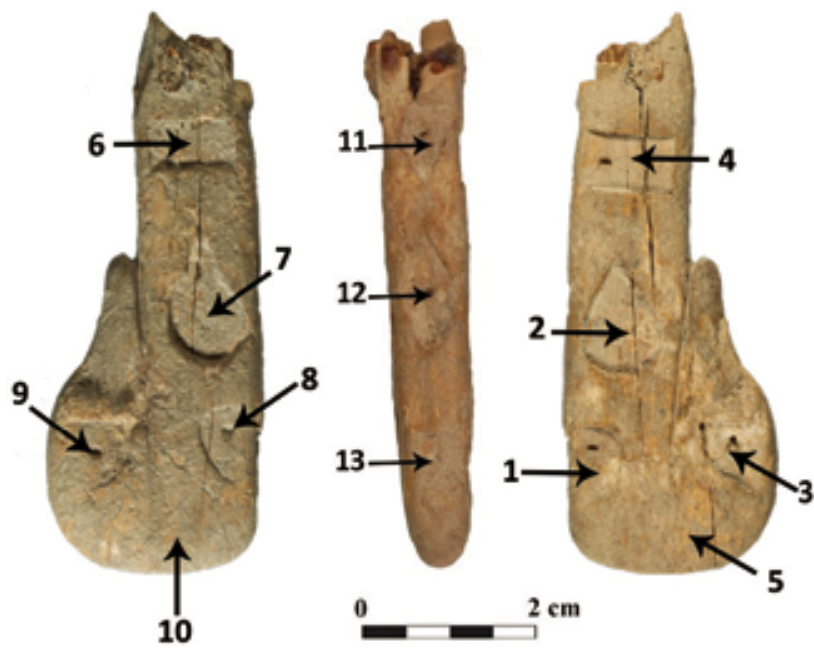

\begin{tabular}{|c|c|c|c|c|c|c|}
\hline ID & P2O5 & CaO & Fe & Sr & Sn & Pb \\
\hline CM1 & 6,85 & 28,02 & 1,74 & 0,10 & $<$ LOD & 0,01 \\
\hline CM2 & 5,62 & 20,84 & 0,94 & 0,08 & 0,38 & $<$ LOD \\
\hline CM3 & 5,88 & 20,80 & 0,68 & 0,07 & $<$ LOD & 0,01 \\
\hline CM4 & 1,98 & 16,61 & 1,15 & 0,09 & 0,55 & 0,03 \\
\hline CM5 & 6,48 & 28,55 & 1,57 & 0,10 & $<$ LOD & 0,01 \\
\hline CM6 & 2,19 & 15,25 & 1,11 & 0,08 & 0,48 & $<$ LOD \\
\hline CM7 & 3,10 & 17,93 & 0,91 & 0,09 & 0,92 & $<$ LOD \\
\hline CM8 & 2,61 & 21,99 & 1,34 & 0,10 & $<$ LOD & 0,01 \\
\hline CM9 & 6,09 & 24,80 & 0,89 & 0,07 & $<$ LOD & 0,01 \\
\hline CM10 & 4,97 & 30,03 & 1,72 & 0,10 & $<$ LOD & 0,01 \\
\hline CM11 & 1,92 & 22,47 & 2,13 & 0,08 & 1,18 & 0,01 \\
\hline CM12 & 5,06 & 22,08 & 1,43 & 0,10 & 0,77 & $<$ LOD \\
\hline CM13 & 2,10 & 24,57 & 1,99 & 0,09 & $<$ LOD & 0,01 \\
\hline
\end{tabular}

FIG. 6. Puntos de análisis y resultados obtenidos mediante análisis pXRF a través de la aplicación Geochem en CM. 


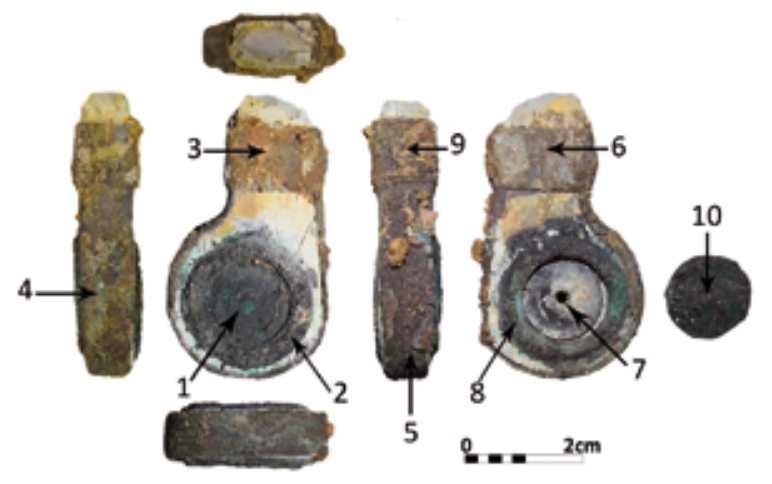

\begin{tabular}{|c|c|c|c|c|c|c|c|c|c|}
\hline ID & Al & Ti & Fe & Ni & Cu & As & Ag & Sn & Pb \\
\hline PLL1 & $<$ LOD & $<$ LOD & 0,36 & 0,11 & 87,58 & 0,57 & 0,51 & 7,28 & 2,74 \\
\hline PLL2 & $<$ LOD & $<$ LOD & 0,51 & 0,07 & 65,10 & $<$ LOD & 9,21 & 3,21 & 20,35 \\
\hline PLL3 & $<$ LOD & 0,13 & 2,85 & 0,19 & 1,25 & 0,02 & 89,88 & 0,60 & 0,11 \\
\hline PLL4 & $<$ LOD & 0,04 & 1,67 & 0,19 & 10,87 & 0,03 & 84,75 & 0,74 & 0,27 \\
\hline PLL5 & $<$ LOD & 0,18 & 1,66 & 0,20 & 6,06 & 0,02 & 89,40 & 0,32 & 0,33 \\
\hline PLL6 & $<$ LOD & 0,03 & 1,83 & 0,23 & 5,36 & 0,04 & 90,05 & 0,36 & 0,64 \\
\hline PLL7 & $<$ LOD & $<$ LOD & 1,04 & 0,14 & 35,50 & 1,20 & 15,92 & 1,00 & 43,16 \\
\hline PLL8 & $<$ LOD & 0,02 & 0,89 & 0,09 & 45,50 & $<$ LOD & 23,47 & 0,84 & 27,12 \\
\hline PLL9 & $<$ LOD & 0,08 & 2,78 & 0,20 & 0,80 & 0,03 & 92,06 & 1,29 & 0,05 \\
\hline PLL10 & 3,98 & $<$ LOD & 0,23 & 0,09 & 90,17 & 0,85 & 0,06 & 3,56 & 0,37 \\
\hline
\end{tabular}

FIG. 7. Puntos de análisis y resultados obtenidos mediante análisis PXRF a través de la aplicación Alloys sobre el mango PLL.

Los valores de $\mathrm{Sn}(0,38-1,18 \%)$ se detectaron en los puntos 2, 4, 6, 7, 11 y 12 que corresponden a algunos rebajos. Estos niveles de estaño podrían estar relacionados con el uso de este metal para adherir las incrustaciones, como se apreció también en TM $(0,02-15)$ y Ls1 $(0,02-18,4)$, que las mantienen, $y$ en EC $(0,04-4,54 \%)$ у СвА2 $(0,20-0,86)$, donde no se conservan (Blasco-Martín et al., 2019: tab. 2).

\subsubsection{Mango de El Puntal dels Llops - PLL-}

De este mango se han analizado sendas arandelas y placas circulares de bronce, en ambas caras del talón, además del revestimiento metálico de sus laterales y la virola que lo sujeta, cuya naturaleza a nivel macroscópico no era posible determinar debido a su alto nivel de alteración. Para la decoración hemos empleado el método Alloys, apropiado para caracterizar materiales metálicos. Los resultados muestran que en los puntos 1, 2, 8, 10 -arandelas y placas- los valores más elevados son los de $\mathrm{Cu}$ $(45,50-90,17 \%)$ mientras $\mathrm{Pb}(0,37-27,12 \%)$ y $\mathrm{Ag}$ $(0,37-27,12 \%)$ tienen una gran variabilidad en su contenido junto a elementos con porcentajes más bajos o ausentes ( $\mathrm{Sn}, \mathrm{Fe}, \mathrm{Ti}, \mathrm{As}, \mathrm{Ni}, \mathrm{Al}$ ) (Fig. 7).

Asimismo, se ha podido identificar que el revestimiento y la virola metálicos están realizados en plata con un elevado porcentaje de pureza, siendo los niveles de Ag en los puntos 3, 4, 5, 6 y 9 de entre el $84,75 \%$ y el $92,06 \%$ (Fig. 7).

Por su parte, en los puntos 2, 7 y 8 los valores de $\mathrm{Cu}(35,5-65,1 \%)$ y de $\mathrm{Pb}(20,35-43,16 \%)$ mantienen valores de Ag elevados (9,21-23,47\%) en comparación con otros puntos en los que este metal no es el mayoritario. Los datos muestran en los puntos 1, 2, 7, 8 y 10 la presencia de bronce cuyas diferencias, especialmente 2,7 y 8 , de un lado, y 1 y 10 , de otro, se relacionan con la formación de óxidos de cobre en la superficie; de hecho, la pátina oscura verdosa es característica de los óxidos de cobre como se refleja en los puntos 1 y 10 , con un elevado porcentaje de este metal. Un conjunto de factores relacionados con procesos de manufacturación, postdeposicionales y de conservación han dado lugar a la formación de óxido en distintas áreas de la pieza que han podido alterar el resultado de los análisis. El punto 10 es especialmente interesante pues está tomado en el disco metálico desprendido, lo cual supone que su medida no tiene interferencias de otros metales. Presenta el porcentaje más elevado de $\mathrm{Cu}(90,17 \%)$, además de $\mathrm{Sn}(3,56 \%)$, $\mathrm{Pb}(0,37 \%)$ y los niveles más bajos de $\mathrm{Ag}(0,06 \%)$. Composición diferente a la proporcionada por SAC especialmente comparando los valores de estaño y plomo (Fig. 5). También el alto porcentaje de $\mathrm{Pb}$ en el punto 7 está relacionado con la formación de óxidos de plomo en la superficie del marfil.

Además, hay que tener en cuenta que en algunos puntos medidos por pXrF, como es el caso del punto 7, el tamańo del instrumento de medida, la posición y la distancia de trabajo influyen en los datos obtenidos. Por ello, para su interpretación se ha evitado desarrollar hipótesis basadas en medidas obtenidas en puntos críticos excepto en los puntos 2 
y 8 , que corresponden a dos arandelas de bronce colindantes al revestimiento de plata -puntos 4 y 5 -. Considerando los aspectos mencionados, las dos arandelas de bronce tienen una proporción elevada de plata con 9,21 y $23,47 \%$ y de plomo con 20,35 y $27,12 \%$-puntos 2 y 8 -.

\section{2. $F T-N I R$}

\subsubsection{Mango de Coll del Moro - $\mathrm{CM}-$}

La Fig. 8 muestra los espectros NIR de los puntos analizados de CM expresados en unidades $\mathrm{Ku}$ belka-Munk. Dichos espectros promediados se muestran sin ningún procesamiento previo de los datos, en una región entre 9000 y $4000 \mathrm{~cm}^{-1}$. Todos ellos presentan bandas de absorción alrededor de 7200 y $5220 \mathrm{~cm}^{-1}$ relacionadas con el modo de combinación de flexión de las especies $\mathrm{H} 2 \mathrm{O}$ y el sobretono de estiramiento del $\mathrm{OH}$ - del agua. En la región de 5000-5308 $\mathrm{cm}^{-1}$, se puede observar el modo de combinación de estiramiento y flexión de $\mathrm{H} 2 \mathrm{O}$, propio de una hidroxiapatita de calcio coloidal libre de carbonatos y sintética. Además, una banda a $6982 \mathrm{~cm}^{-1}$ puede atribuirse al sobretono de estiramiento del $\mathrm{OH}$ - (Blasco-Martín et al., 2019).

En este caso, no se han podido identificar las bandas correspondientes a los sobretonos de las resinas naturales (4353-4343) como sí pudimos distinguir previamente en los mangos TM y Ls1 (Blasco-Martín et al., 2019).

En el mango См no se conservan evidencias macroscópicas de incrustaciones adheridas en los rebajos, lo que podría explicar la ausencia de resultados concluyentes tras los análisis NIR. No obstante, mediante prXf sí que se han obtenido débiles indicios de la presencia de estaño como en ЕС у Сва2.

\section{Una artesanía de prestigio}

El significado de los objetos como identificadores de prestigio social ha sido estimado de múltiples formas a lo largo de la Antigüedad. El valor o el prestigio no se les atribuye únicamente en función de sus cualidades intrínsecas, sino que depende del contexto sociocultural.

En Arqueología, el modelo de economía de bienes de prestigio es una propuesta heredada desde la Antropología (Meillassoux, 1960; Dupré y Rey, 1973; Sahlins, 1983 [1974]; Ekholm, 1972). Se ha aplicado en algunos estudios arqueológicos como los de Frankenstein y Rowlands (1978) y Frankenstein (1997) para las necrópolis del Hallsttat D en el so de Alemania, o los de Aubet para las necrópolis tartésicas (Aubet, 1993 y 2005; Aubet et al., 1996).

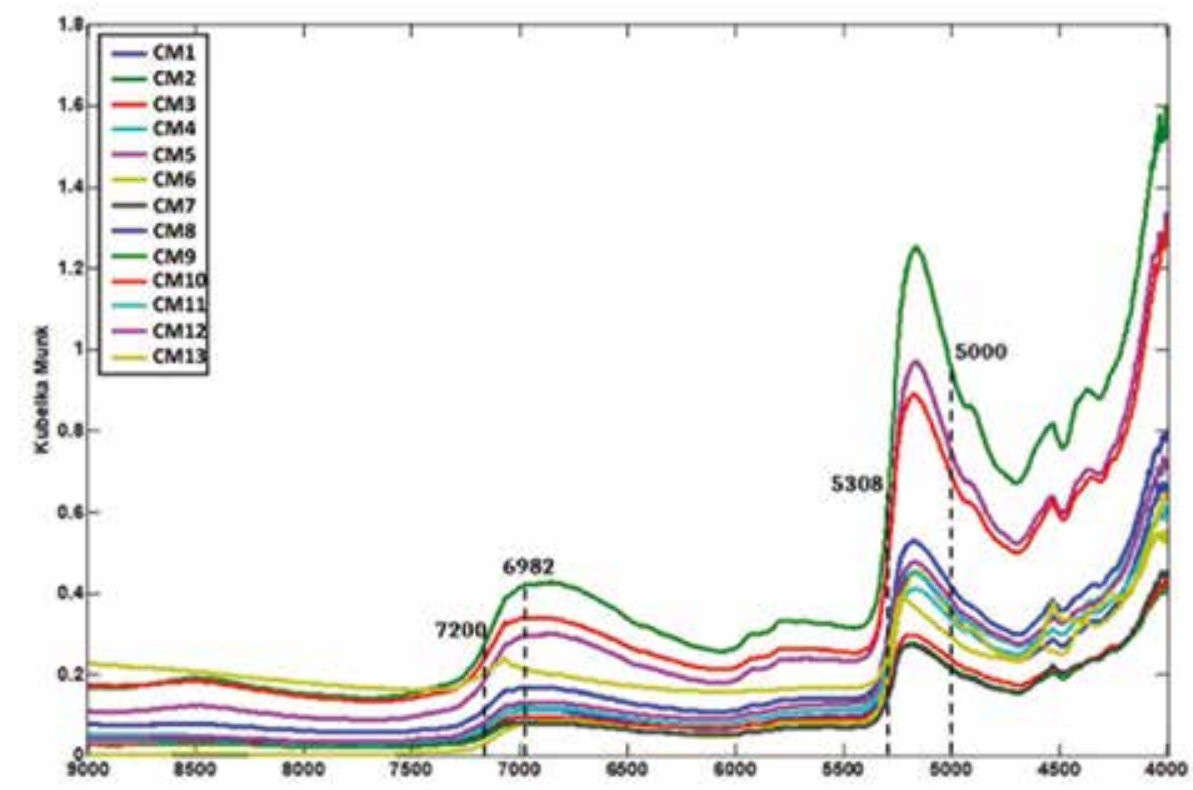

FIG. 8 Espectros NIR obtenidos del análisis de CM en la región entre $4000-9000 \mathrm{~cm}^{-1}$ sin tratamiento previo; las bandas indicadas reflejan los valores de: $7200 \mathrm{~cm}^{-1}\left(\mathrm{H}_{2} \mathrm{O}\right) ; 6982$ $\mathrm{cm}^{-1}\left(\mathrm{OH}^{-}\right) ; 5308-5000 \mathrm{~cm}^{-1}\left(\mathrm{H}_{2} \mathrm{O}\right)$. 
El antropólogo A. Gallay seńala la necesidad de definir el concepto bien de prestigio, siempre y cuando se disponga del contexto histórico o arqueológico en que se hallan dichos bienes. Reconoce una serie de características intrínsecas asociadas al prestigio de los objetos, entre ellas: la escasez de materias primas empleadas en su producción, por ser excepcionales, exóticas, remotas y, por tanto, de difícil obtención; la complejidad de la cadena operativa para su elaboración, que implica una considerable inversión técnica y energética que revela una especialización artesanal; el hecho de que se encuentran al margen de las necesidades de la vida diaria; y su integración en redes o circuitos no comerciales para transformarse en bienes de prestigio, perdiendo así su valor de uso y adquiriendo valor de signo (Gallay, 2010: 30 y 39). Los análisis morfotécnicos y arqueométricos realizados, así como los aspectos teóricos señalados, evidencian problemáticas como la especialización artesanal y la transmisión del saber hacer, los contactos a larga distancia y la herencia de los bienes e incluso el concepto de bien de prestigio en sí mismo.

\subsection{Materias primas y decoración}

El marfil de proboscídeo utilizado en los mangos es de procedencia foránea, ya sea africano o asiático, por lo que el acceso al mismo era diferencial, dependiente de las rutas comerciales y de las capacidades económicas de artesanos y usuarios y, por tanto, es una materia prima minoritaria, sobre la que la experiencia acumulada de trabajo está restringida a un número menor de artesanos. Además, en estos mangos hemos documentado el uso conjunto de otras materias primas para su decoración: el ámbar y el estańo, el bronce y la plata, sin olvidar que forman parte de útiles compuestos y no pueden desligarse del elemento activo al que enmangan, que es de hierro.

El análisis FT-NIR determinó que las incrustaciones conservadas en TM y LS1 (Figs. 1 y 3, tipo 1) corresponden a resinas naturales como el ámbar (Blasco-Martín et al., 2019). De igual forma, mediante pXrF, se detectó el uso del estaño para adherir estas

Ediciones Universidad de Salamanca / 요 incrustaciones, sustancia que probablemente modificaría el brillo de los ámbares traslúcidos (Vigil, 1969). Otros cuatro mangos, СвА1, СвА2, ЕС у См (Figs. 1 y 3), ofrecen decoración de rebajos de formas variadas, pero no han conservado las incrustaciones. Sin embargo, el uso de técnicas decorativas similares nos permite proponer que estuvieran decorados con la misma materia prima -ámbar- y sustancia adherente -estaño-, como parecen reflejar los análisis químicos realizados (Fig. 6 y Blasco-Martín et al., 2019).

El ámbar tiene fuentes de aprovisionamiento destacadas en afloramientos del Báltico y Sicilia y más limitadas en la Península Ibérica, especialmente en la cuenca vasco-cantábrica -Peña Cerrada, Álava y El Soplao, Cantabria- y en la del Maestrazgo -San Just, Teruel- (Murillo-Barroso et al., 2018: 4-6). Esta resina apenas se ha identificado en objetos de la Edad del Hierro, al igual que ocurre con el marfil.

El empleo conjunto de ámbar y marfil no se conocía en el ámbito cultural ibero. Sin embargo, está muy bien documentado en el mundo etrusco (Formigli, 2004; Naso, 2007: 20 y 22, figs. 9 y 1; Negroni, 2011).

El estaño, por su parte, es de uso habitual desde el II milenio a. C. para elaborar bronce y se ha identificado también en orfebrería, utilizado en aleación con el plomo como soldadura blanda (Perea, 1990: 138). Con una finalidad semejante, como hemos apuntado, en los mangos analizados se empleó como adherente de las incrustaciones de ámbar.

Las placas circulares de bronce conservadas en SAC y PLL no supusieron un problema de acceso a la materia prima, pues su uso está generalizado en época ibérica. Por comparaciones morfotécnicas, el ejemplar св, con el talón fragmentado, también presentaría este tipo de decoración. Además, cabe plantear que los rebajos circulares de mayor tamaño en СвА1, СВА2, Тм у LS1 contarían también con placas de bronce que se sumarían a las incrustaciones de ámbar, mostrando así diferentes gamas de colores: el del propio marfil, el del ámbar junto al estaño y el del bronce con dos aleaciones detectadas, que producen un efecto cromático, remarcando de ese modo la 
ornamentación de las piezas y resultando, por tanto, más llamativas visualmente. El cobre también se ha utilizado en SAC para el remache que sujeta la hoja de hierro a la espiga (Fig. 5, puntos 3 y 10).

El uso de la plata se ha constatado en un único ejemplar-PLL-. Es un metal de acceso restringido, de alta consideración y símbolo de poder, utilizado para elaborar ornamentos personales -anillos, fíbulas, pulseras y collares, entre otros-; instrumentos de intercambio -lingotes, plata acuñada, recortes, etc.-, y para la manufactura de vajillas de lujo como los conjuntos de Castellet de Banyoles, en Tivissa, Tarragona, o Vallejo de la Viña, en Abengibre, Albacete, por citar algunos hallazgos; también fue empleada para decorar broches, hebillas de cinturón y armas mediante damasquinado.

El mango del Puntal dels Llops es, hasta el momento, el único conocido en el mundo ibérico en el que se emplean conjuntamente marfil, plata y bronce (Figs. 1 y 7). Los paralelos más cercanos los encontramos en la necrópolis de la Joya, Huelva. En la Tumba 17, datada entre los ss. VII y vi a. C., se recuperaron formando parte de un suntuoso ajuar, donde destacan los restos de un carro, dos cuchillos de hierro de hoja curva con enmangues de marfil sujetos por clavos de plata. En uno de ellos, entre la hoja y los dos clavos más cercanos a esta, hay una anilla de bronce que, por la posición que ocupa, podría ser una reparación. Se trata, por tanto, de mangos en los que, si bien de forma distinta a PLL, se emplean marfil, plata, bronce y hierro. En esta misma tumba se recuperó una arqueta de marfil y bronce que contaba con dos bisagras de plata maciza. Por otra parte, en la Tumba 18 se identificó otro cuchillo de hierro con cachas de madera sujetas mediante seis remaches y una abrazadera de plata. Sus descubridores abogan por una procedencia fenicia para estas piezas ebúrneas que llegarían a la Península Ibérica a través del comercio (Garrido y Orta, 1978: 103-108, 142 y 184).

Por último, las hojas de hierro de los cuchillos no supusieron un problema de acceso a la materia prima, ya que se trata de un metal y de una actividad metalúrgica habitual, de sobra conocida en época ibérica.

\subsection{Cronología y contexto: el valor social}

Los cuchillos son los primeros útiles de hierro fabricados en la Península Ibérica a partir del s. VIII a. C., tanto en asentamientos como formando parte de los ajuares funerarios. Aunque existe un magnífico relieve en el monumento funerario de Pozo Moro, en Chinchilla de Montearagón, Albacete, con una escena en la que se puede ver a un ser fantástico con un cuchillo en la mano a punto de matar a un animal (Almagro-Gorbea, 1978: lám. III), otros hallazgos en tumbas sin evidencias inequívocas de animales asociados (Vives-Ferrándiz y Mata-Parreño, 2020: 150) indican que estos cuchillos no tuvieron únicamente un uso sacrificial. Serían más bien útiles de prestigio en los primeros siglos de la siderurgia, razón por la cual se depositaban en tumbas. A partir del s. v a. C. su generalización entre todas las capas sociales redujo su relevancia social y ritual en favor de las panoplias, convirtiéndose en 'simples' herramientas (Mateos y Sánchez, 2014: 146). Sin embargo, entendemos que no todos los útiles pueden considerarse de la misma manera y que las empuñaduras expuestas, decoradas o no, así como las armas en general, y, sobre todo, la calidad del hierro, nos remiten a objetos destacados, de alta consideración social reflejada no solo en los contextos funerarios, sino también en los asentamientos.

De los 11 mangos de marfil, tres fueron recuperados en necrópolis, siendo precisamente estos los que tienen las cronologías más antiguas: s. IV a. C. en el caso de EC; primer cuarto de esa misma centuria para EM, y una horquilla más amplia, entre los ss. IV-III a. C., para сва1 (Fig. 3). En los dos primeros ejemplares vale la pena enfatizar la relevancia de los contextos que nos permiten trazar un marco de referencia, a través de la asociación con otros elementos de la cultura material, de su importancia social y simbólica.

El mango EC formaba parte del ajuar de la Tumba 294, donde se documentan ornamentos, objetos destacados como un anillo de plata, el mango de marfil y cerámica ática (Cuadrado, 1987: 504-506 y fig. 219-т. 294). Estas piezas evidencian una posición social preeminente de la persona enterrada, de la que se desconocen el sexo y la edad. 
Por su parte, el mango EM se recuperó en un silicernium, es decir, una ceremonia que refuerza los vínculos colectivos y consagra la memoria de aquellos que se han ido. En este tipo de banquetes se podía ofrecer el sacrificio de un animal a las divinidades. ¿Pudo este cuchillo con mango de marfil haber participado en esta acción revestida de simbolismo? Según reflejan los datos zooarqueológicos se consumieron in situ diversos animales, fundamentalmente domésticos -Ovis aries/Capra hircus, Sus domesticus, Bos taurus, Canis familiaris y Cervus elaphus-. Además, se recuperaron numerosas evidencias de vajilla de mesa, sobre todo, platos y copas; ánforas y ollas de cocina (Monraval y López Piñol, 1984: 150).

En cambio, los ocho mangos procedentes de contextos de hábitat tienen una cronología centrada entre los ss. III-II a. C., similar a la de los peines de marfil ibéricos, de los que solo uno de los 20 registrados se ha encontrado en necrópolis (Mata et al., 2017a). Podría plantearse que en estas centurias los objetos ebúrneos son un bien que forma parte del proceso de ostentación cotidiano, del 'más acá', que se pueden heredar y que forman parte de los bienes domésticos familiares y no se amortizan en enterramientos. La limitada disponibilidad y circulación de estos mangos, su valor por sus materias exóticas y de alta consideración - marfil, ámbar y plata- y su aspecto lujoso podrían constituir una manifestación más de una sociedad aristocrática en busca de signos para distinguirse en vida.

En relación con estas consideraciones, debemos referirnos al Puntal dels Llops, pues no resulta trivial que las únicas piezas de marfil del yacimiento, este mango y un peine con decoración incisa (Bonet y Mata, 2002: 68, 162, figs. 72-4128 y 176), estén en el mismo espacio, el Dpto. 4, identificado como una estancia aristocrática, de marcado carácter masculino. La ostentación de las élites se refleja en la propiedad de estas piezas realizadas en una materia prima exótica, escasa y valiosa como el marfil y, en el caso del mango, trabajada junto al bronce y la plata. Suponen una plasmación material de diferenciación social. En este fortín no hay más objetos de plata, lo que remarca aún más la relevancia del mango. Además, las evidencias ${ }^{5}$ del proceso de la primera copelación del plomo apuntan a una transformación de la plata en este u otro asentamiento cercano -Ferrer, en Bonet y Mata, 2002: 200-206; Rovira, en Guérin, 2003: 369-370-. Con los análisis realizados (Fig. 7) podemos plantear que, al menos las arandelas y el refuerzo argentífero del mango, se hicieron en el mismo yacimiento o con materias primas transformadas en este.

Diversas piezas singulares encontradas como pebeteros, asador, cerámicas importadas y un sistema ponderal, entre otras, avalan la capacidad de algunos de sus ocupantes para conseguir bienes de gran valor a cambio de tareas de transformación metalúrgica.

El ejemplar SAC proviene del Dpto. c del Edificio 3, un recinto de pequeñas dimensiones que destaca, entre otros hallazgos, por la notoria presencia de material cerámico decorado ibérico, cerámicas importadas, una lanza de hierro, unas pinzas de bronce y cantos trabajados (Jornet, 2017: 83-91). En el mismo departamento se documentó una fosa con restos de mandíbulas de ovicaprino, interpretada como un posible ritual de fundación (Jornet, 2017: 277). Ambos, Pll y SAC, se han encontrado en áreas con un significado social fuera de lo cotidiano.

El ejemplar CM, el más moderno identificado, es una de las piezas más destacadas recuperadas en una de las estancias de un edificio de época romano-republicana con posible función de control territorial (Jornet et al., 2016: 355 y 2020: 123-124). La estancia contenía también una plaquita de hueso con perforaciones, un canto rodado con cinco incisiones en la base -posible ponderal-, vajilla ática y campaniense y abundante cerámica ibérica, sobre todo de almacenaje.

En cambio, el mango Св se encontró en un espacio abierto junto a abundante material cerámico, tanto de importación como ibérico, y pequeñas

5 Se trata de cinco grandes planchas de plomo, de más de $340 \mathrm{~kg}$, recuperadas en los Dptos. 2, 3, 5 y 6, goterones de plomo de los Dptos. 2, 3, 4 y 5 y restos de un hogar de $1 .^{a}$ copelación en el Dpto. 2 (Bonet y Mata, 2002: 200-203). 
piezas metálicas. Desafortunadamente, este contexto no aporta información sobre sus posibles propietarios (Guérin, 2003: 77).

Por otra parte, тм fue recuperado en un phylacterion de la fortaleza datada en la primera mitad del s. III a. C. cuyos materiales asociados no se han publicado; y de los ejemplares CBA2, Ls 1 y Ls2 se desconoce su lugar de hallazgo dentro de los oppida.

En síntesis, las élites demandaron, con el paso del tiempo, un objeto diferente que aunaba un útil funcional con materias primas excepcionales para mostrar nuevos símbolos de prestigio y de poder. $\mathrm{Su}$ mayor presencia en lugares de hábitat puede evidenciar la herencia de los bienes familiares o la transmisión de estatus social. A favor de esta idea se encuentra el factor cronológico, pues los mangos de mayor antigüedad se fechan en el s. IV a. C., amortizados en necrópolis, mientras que la mayoría tienen una datación entre los ss. III y II a. C.

\subsection{Artesanía especializada}

En el estado actual de la investigación, la existencia de artesanías especializadas en la cultura ibérica es un aspecto demostrado arqueológicamente. La demanda y producción de objetos de lujo como piezas únicas realizadas por encargo ya fue planteada hace años para la cerámica con decoración compleja (Olmos, 1987) y, años más tarde, para la producción de falcatas damasquinadas (Quesada et al., 2000: 294).

Los mangos son objetos compuestos por varios elementos fabricados por separado y unidos posteriormente para formar un conjunto armónico que tiene no solo una función, la de cuchillo, sino un significado $\mathrm{y}$, por tanto, fueron cuidadosamente diseńados. Tan importantes como el componente estructural de las piezas, marfil, son los detalles de la ornamentación, pues en ellos se sintetiza una buena parte de su significado simbólico. La taracea muestra un dominio técnico y artístico, y el color y brillo proporcionado por el ámbar y los metales es un recurso previsto por el artesano para conseguir el efecto deseado: ostentación.
Por ello, estos cuchillos constituyen una clara evidencia de una artesanía especializada, caracterizada por la ejecución de objetos complejos, por un verdadero dominio técnico y artístico y por el acceso a materias primas y conocimientos técnicos especializados. Son una muestra de una producción hecha por artesanos que conocen y controlan perfectamente las técnicas y pueden permitirse trabajar, por su habilidad y por su posición social cercana a las élites, unas materias primas de elevado coste.

A partir de estas reflexiones, planteamos dos hipótesis para explicar su producción:

1. Que se trate de artesanos que dominan o han aprendido las técnicas de manufactura del marfil y de la taracea en territorio peninsular. Ello supondría la llegada a la península de colmillos enteros o en estadios secundarios de su elaboración (Celestino, 1997: 364; Mederos y Ruiz, 2004), si bien es cierto que, en época ibérica, a diferencia de lo que sucede en la prehistoria reciente (López Padilla, 2001: 250), no se aprecia un aprovisionamiento generalizado y constante de marfil. Cabe pensar en un descenso de su comercio a lo largo de la Primera y Segunda Edad del Hierro y no será hasta la llegada de cartagineses y romanos cuando de nuevo se atestigüe un auge de esta materia prima.

Estos artesanos, más que trabajar en un lugar fijo, podrían ser itinerantes ${ }^{6}$, transportando consigo herramientas, saber-hacer e ideas, lo cual explicaría la existencia de piezas similares en lugares distantes (Figs. 1 y 2). Propuesta que también hemos apuntado para los peines de marfil (Mata et al., 2017a).

De ser artesanos itinerantes, la detección de espacios de trabajo puede resultar prácticamente imposible ya que carecerían de un lugar estable. No obstante, en la Hispania romana, donde la

6 Una propuesta similar se ha hecho para la producción de armas y ornamentos con damasquinados en plata. Esto explicaría también la copia o imitación de piezas con un estilo menos depurado por parte de artesanos no especializados. Según Quesada et al. (2000: 298), “... encaja con los modelos conocidos, tiene paralelos en otros lugares, y podría además aplicarse a otros productos de lujo...”, una reflexión que secundamos. 
artesanía sobre el marfil es abundante, tampoco se ha localizado taller eborario alguno (Rodríguez Martín, 2014: 363).

Independientemente de la itinerancia o no, las herramientas utilizadas no sirven para detectar espacios de trabajo específicos, ya que pueden emplearse para otras actividades como la orfebrería y la ebanistería: pequeñas sierras, cuchillos o cuchillas, punzones, compases, materiales abrasivos, cinceles, taladros de arco. Igualmente, se utilizarían aceites, grasas, agua y sustancias adherentes, tanto el estaño identificado, como algún tipo de resina o compuesto vegetal que no hemos identificado, bien por el estado de conservación de las piezas, bien por las técnicas analíticas empleadas.

2. Que los cuchillos llegaran a la Península Ibérica totalmente manufacturados, a través del comercio mediterráneo. No conocemos ejemplares exactamente iguales a estos en otros yacimientos extrapeninsulares, aunque no se puede descartar que existan piezas similares y no hayan sido publicadas o no se les haya prestado la suficiente atención. El ejemplo más parecido procede de Antibes, en el sur de Francia, datado en el s. v a. C.; es una plaquita de marfil con decoración incisa y rebajos para la incrustación de elementos en otro material, no conservado, que se ha interpretado como las cachas de un cuchillo o espada corta (Hermary, 2013: 56-57). Sin embargo, dada la existencia de peines y mangos de marfil con atributos compatibles con el gusto indígena, algunas reparaciones documentadas y las concentraciones significativas que se dan en asentamientos con una cronología similar, como Cerro de las Cabezas, en Valdepeñas, Ciudad Real, o La Serreta (Mata et al., 2017a), nos parece más probable la primera propuesta.

Otra cuestión es si se trata de piezas elaboradas por un único artesano o por varios en colaboración. En la fabricación de útiles y armas enmangados, los procesos metalúrgicos para generar la parte activa y la elaboración de los mangos deberían estar estrechamente ligados teniendo en cuenta las características morfométricas de ambas partes.

Lo mismo ocurre con las incrustaciones, que están sujetas a la forma de los rebajos en los enmangues. Por ello, es probable que un solo artesano llevara a cabo todo el proceso de producción de estos útiles compuestos, que no pueden considerarse terminados sin la hoja o sin el mango ${ }^{7}$. En otros contextos mediterráneos, especialmente en el mundo micénico, egipcio y etrusco, diferentes hallazgos de objetos en proceso de producción han evidenciado que eran los mismos artesanos los que trabajaban el ámbar, el marfil, la pasta vítrea, el hueso o el cuerno (Causey et al., 2012: 83) o compartían los mismos espacios (Costin, 2012: 187).

Unos comentarios aparte merecen los mangos Ls2 y EM, carentes de decoración (Fig. 3, tipo 3). Nos planteamos si se trata de piezas sin terminar en las que, tras dar la forma del mango, no se hubiera llevado a cabo la ornamentación, último paso en la cadena operativa (Mata et al., 2018: 119). No obstante, la ausencia de decoración también puede deberse a una elección estilística, algo especialmente evidente en EM que formó parte de un ritual funerario de comensalía, y, por tanto, se trata de una pieza acabada. En cambio, en Ls2 llama la atención la forma del talón menos redondeada que en el resto y la ausencia de los elementos de sujeción o de la hoja (Fig. 1). Si se tratara de una pieza en proceso de elaboración permitiría corroborar su producción o, al menos, su finalización en territorio peninsular, adaptándolo a los gustos del consumidor. En este yacimiento hay, además, un peine de marfil con una modificación de la pieza original, posiblemente por rotura, lo que aboga por la presencia de artesanos especialistas en La Serreta (Mata et al., 2017a: 148, fig. 7,5.1).

7 Todavía hoy, en los talleres tradicionales de navajas de Albacete es el mismo artesano el que elabora la cuchilla metálica y la empunadura, lisa o decorada, adaptando la una a la otra. Un ejemplo actual puede verse en el reportaje a M. Fernández. https://www.youtube.com/watch?v=rSUKUKzVCc0 (consultado 17/03/2020). 


\section{Conclusiones}

Los cuchillos con mangos de marfil son objetos de prestigio, elaborados en una materia prima alóctona al territorio peninsular y de reconocido valor económico y social. No todo el mundo tendría acceso a piezas como estas, más aún si tenemos en cuenta los ejemplares que tienen incrustaciones en ámbar adheridas con estaño y los decorados con apliques metálicos, especialmente en el caso de la plata, tal y como han identificado los análisis pXRF y FT-NIT. Para su elaboración se requirieron materias exóticas de difícil acceso -marfil y ámbar-, otras de acceso restringido - plata y estañoy algunas más accesibles (hierro y cobre). El marfil y el ámbar son cada vez más visibles en la cultura material de los iberos. Su presencia indica que, además de participar en las vías de distribución, amplían el valor simbólico y de prestigio de ciertos objetos, como los cuchillos con mango de marfil, respecto al que hasta ahora se les había asignado. En un futuro próximo, sería idóneo desarrollar proyectos de análisis para determinar el origen de estas materias primas, tal como se ha hecho, por ejemplo, con las cuentas de ámbar de la necrópolis de El Ceremeño, en Herrería, Guadalajara, de origen báltico (Cerdeño et al., 2012), o con los marfiles calcolíticos del sureste peninsular (Schuhmacher y Banerjee, 2012). Con esta información se podrían precisar las rutas comerciales en la Edad del Hierro.

Los metales, por su parte, son elementos estratégicos, de elevado valor socioeconómico, especialmente en el caso de la plata, siendo un bien de intercambio no solo en el mundo ibérico, sino en todo el ámbito mediterráneo. Por tanto, su combinación inédita junto al marfil en el ejemplar del Puntal dels Llops pone de manifiesto la capacidad de acceder a esa materia prima y de ostentación de sus propietarios.

La pervivencia de estos mangos entre los ss. IV-II a. C. no permite hablar de una producción estandarizada y de uso cotidiano, sino todo lo contrario. Los cuchillos tendrían habitualmente enmangues de madera, asta o hueso y, en este sentido, los objetos analizados nos permiten trazar la excepcionalidad y

Ediciones Universidad de Salamanca / 요요 valía de la artesanía del marfil en la Segunda Edad del Hierro, una artesanía que, como reflejan estos útiles, requeriría de la colaboración entre varios artesanos o del dominio total, por una misma persona, de la manufactura de diferentes materias primas.

Los análisis sobre los peines ebúrneos, objetos también complejos y de elevada valía social, económica y simbólica, producidos en la península, han puesto de manifiesto la transmisión de conocimientos y técnicas, maestro-discípulos, entre los artesanos iberos que trabajaban el marfil (Mata-Parreño et al., 2017b). Es lógico pensar que los mismos artesanos elaboraran mangos y peines. La propuesta de artesanos itinerantes explicaría las claras semejanzas y pequeńas particularidades detectadas en las piezas que pueden indicar adaptación al gusto local o varias manos detrás de los objetos. Por ejemplo, Ls1 y TM (Fig. 1) son tan iguales que cabe pensar que solo pudo hacerlos la misma persona.

Los cuchillos se realizarían por encargo directo de las élites locales para legitimar su preeminencia social. En ese sentido, constituyen un marcador social vinculado a los grupos de poder. Por último, cabe remarcar que, a partir del s. III a. C., pudieron heredarse, ya que no están amortizados en tumbas, e intercambiarse en ceremonias de reciprocidad, perdiendo su valor de uso y adquiriendo valor distintivo y de signo.

\section{Bibliografía}

Almagro-Gorbea, M. (1978): "Pozo Moro y la formación de la Cultura Ibérica", Saguntum, 13, pp. 227250.

Atrián, P. (1976): El yacimiento ibérico del Alto Chacón (Teruel). Campañas realizadas en 1969-1970-1971 y 1972. Excavaciones Arqueológicas en España, 92. Madrid.

Aubet, M.a E. (1993): "Aproximación a la estructura social y demográfica tartésica”. En Tartessos 25 años después (1968-1993). Actas Congreso Conmemorativo del $v$ Symposium Internac. de Prehistoria Peninsular. Jerez de la Frontera, pp. 401-410.

Aubet, M.a E. (2005): "El 'Orientalizante': un fenómeno de contacto entre sociedades desiguales". En 
Celestino, S. y Jiménez Ávila, J. (eds.): El Periodo Orientalizante. Anejos de Archivo Español de Arqueología, xxxv. Mérida, vol. 1, pp. 117-128.

Aubet, M. a E.; Barceló, J. A. y Delgado, A. (1996): "Kingship, Gender and Exchange: the Origins of Tartessian Aristocracy”. En BietTi, A. M. a y Kruta, V. (eds.): The Iron Age in Europe. XIII International Congress or Prehistoric and Protohistoric Sciences (Forli, Italia, 1996). Colloquia, 12. Forlí, pp. 145-161.

Badal, E.; Carrión, Y.; Mata, C. y Fabra, E. (2017): "Mangos y maderas en el mundo ibérico". En XII Congreso Ibérico de Arqueometría (Burgos, 2017). Burgos, p. 40.

Blasco-Martín, M. (2018): "Una visión comparativa. Piezas de hueso, asta y otras materias primas de El Palomar (Oliete, Teruel)". En Agudo, L.; Duarte, C.; García, A.; Geiling, J. M,; Higuero, A.; NúŃEZ, S.; Rodríguez, F. J. y SuÁrez, R. (eds.): Actas IX Jornadas Jóvenes en Investigación Arqueológica. Santander, pp. 139-146.

Blasco-Martín, M.; Gallello, G.; Soria-Combadiera, L.; Collado-Mataix, E.; Pastor, A. y Mata-Parreño, C. (2019): "Decoration composition of Iberian Iron Age ivory artifacts identified by no-destructive chemical analyses", Archaeological and Anthropological Sciences, 11, pp. 3561-3576. https:// doi.org/10.1007/s12520-018-00775-3

Bonet, H. y Mata, C. (1981): El poblado ibérico del Puntal dels Llops (El Colmenar) (Olocau-Valencia). Serie de Trabajos Varios, 71. València.

Bonet, H. y Mata, C. (2002): El Puntal dels Llops. Un fortín edetano. Serie de Trabajos Varios, 99. València.

CASAS, J. y SOlER, V. (2012): El asentamiento rural ibérico de Saus (Girona). Un ejemplo de explotación agricola en el territorio de Emporion. BAR Intern. Ser., 2390. Oxford: Archaeopress.

Causey, F.; Maish, J.; Khanjian, H. y Schilling, M. (2012): Ancient Carved Ambers in the J. Paul Getty Museum. J. Paul Getty Museum. http://museumcatalogues.getty.edu/amber/contents

Celestino, S. (1997): "Santuarios, centros comerciales y paisajes sacros", Quaderns de Prehistòria i Arqueologia de Castelló, 18, pp. 359-389.

Cerdeño, M. ${ }^{a}$ L.; Martínez, J. A.; Agua, F.; Sagardoy, T. y Monasterio, M. (2012): "Ámbar en la Meseta Oriental durante el bronce Final: yacimientos locales e importaciones bálticas", Trabajos de Prehistoria, 692, pp. 375-384. doi: 10.3989/tp.2012.12098.

Costin, C. L. (2020): "What is a workshop?". En Hodkingson, A. K. y Tvetmarken, C. L. (eds.):
Approaches to the analysis of production activity at archaeological sites. Oxford: Archaeopress, pp. 177-197.

Cundrado, E. (1987): La necrópolis ibérica de El Cigarralejo (Mula, Murcia). Biblioteca Praehistorica Hispana, XXIII. Madrid: csic.

Dupré, G. y Rey, P. P. (1973): "Reflections on the pertinence of a theory of the history of Exchange", Economy and Society, 2 (2), pp. 131-163.

Екноцм, K. (1972): Power and prestige, the rise and fall of the Kongo Kingdom. Uppsala: Skriv Service AB.

Formigli, E. (2004): "El uso del estańo con ámbar para obtener un efecto de color similar al oro en la orfebrería etrusca". En Perea, A.; Montero, I. y García-Vuelta, O. (eds.): Ancient gold technology: America and Europe. Anejos de Archivo Español de Arqueología, xxxiI. Madrid, pp. 91-96.

Frankenstein, S. (1997): Arqueología del Colonialismo. El impacto fenicio y griego en el sur de la Península Ibérica y el suroeste de Alemania. Barcelona: Crítica.

Frankenstein, S. y Rowlands, M. (1978): "The internal structure and regional context of Early Iron Age society in South-Western Germany", Institute of Archaeology Bulletin, 15, pp. 73-112.

Gallardo, J.; García Cano, J. M.; Hernández CaRRIÓn, E. y Ramos, F. (2017): Excavaciones en Coimbra del Barranco Ancho. Jumilla 2015-2016. La Casa M. Murcia.

Gallay, A. (2010): "Une approche anthropologique de la notion de bien de prestige", Bulletin d'Etudes prehistoriques et archeologiques Alpines, XXI, pp. 29-44.

García Cano, J. M. (1997): Las necrópolis ibéricas de Coimbra del Barranco Ancho (Jumilla. Murcia). I. Las excavaciones y estudio analítico de los materiales. Murcia: Univ. de Murcia.

García Cano, J. M.; Page, V.; Ramos, F.; Hernández, E. y GIL, F. (2008): El mundo funerario ibérico en el altiplano ibérico Jumilla-Yecla (Murcia): La necrópolis de El Poblado de Coimbra del Barraco Ancho. Investigaciones de 1995-2004. II.- Las incineraciones y los ajuares funerarios. Murcia: Proyecto Iberos Murcia.

Garrido, J. P. y Orta, E. M. ${ }^{a}$ (1978): Excavaciones en la necrópolis de 'La Joya' Huelva (3. a, 4. a y 5. a campañas). Excavaciones Arqueológicas en España, 96. Madrid.

Grau, I. (1996): "Estudio de las excavaciones antiguas de 1953 y 1956 en el poblado ibérico de La Serreta", Recerques del Museu d'Alcoi, 5, pp. 83-119.

Guérin, P. (2003): El Castellet de Bernabé y el horizonte ibérico pleno edetano. Serie de Trabajos Varios, 101. València. 
Hermary, A. (2013): "Une exceptionnelle plaquette en ivoire découverte lors des fouilles de la place Mariéjol". En Aux origines d'Antibes. Antiquité et Haut Moyen Âge. Antibes: Musée d'Archéologie, pp. 56-57.

JoRnet, R. (2017): El jaciment de Sant Antoni de Calaceit $i$ el poblament ibèric a les comarques del Matarranya $i$ la Terra Alta. Monografies, 15. Barcelona: Museu d'Arqueologia de Catalunya.

Jornet, R.; Belarte, M. C.; Sanmartí, J.; Asensio, D. y Morer, J. (2016): "Noves excavacions al nucli fortificat del Coll del Moro de Gandesa (20142015)". En Actes I Jornades d'Arqueologia de les Terres de l'Ebre. Tortosa, pp. 345-358.

Jornet, R.; Belarte, M. C.; Sanmartí, J.; Asensio, D.; Morer, J. y Noguera, J. (2020): "El Coll del Moro (Gandesa, Tarragona) y su contexto territorial: formación y desarrollo de un asentamiento urbano protohistórico", Trabajos de Prehistoria, 77 (1), pp. 113-129.

Llobregat, E. A.; Cortell, E.; Moltó, J. J. y Segura, J. M. (1992): "El urbanismo ibérico en La Serreta", Recerques del Museu d'Alcoi, 1, pp. 37-70.

López Múllor, A. (2011): "La muralla principal de l'oppidum ibèric del Montgrós (el Brull) i les seves defenses perifèriques", Revista d'Arqueologia de Ponent, 21, pp. 141-156.

López Padilla, J. A. (2001): "El trabajo del hueso, asta y marfil"... Y acumularon tesoros. Mil años de historia en nuestras tierras. Alicante, pp. 246-257.

Martín, A.; Casas, S.; Codina, F.; Margall, J. y De Prado, G. (2004): "La Zona 14 de l'oppidum del Puig de Sant Andreu d'Ullastret. Un conjunt arquitectònic dels segles IV i III AC", Cypsela, 15, pp. 265284.

Mata, C.; Soria, L.; Blasco, M.; Fuentes, M. y CoLlado, E. (2017a): "Peines de marfil y madera de la II Edad del Hierro en la Península Ibérica. Talleres, estilos y otros enredos", Complutum, 28 (1), pp. 141165. dx.doi.org/10.5209/CMPL.58418

Mata, C.; Soria, L.; Blasco, M.; Fuentes, M.; Collado, E.; Mora y E.; Bernabeu, J. (2017b): "Transmission of craftsmanship and circulation of craftsmen in Iron Age Iberian península". En Workshop Contact, circulation, exchange in past societies: approaches from the bone artefacts (Trnava, 2017). Trnava: uisPP Commission Bone Artefact.

Mata-Parreño, C.; Soria-Combadiera, L.; Blasco-Martín, M.; Fuentes-Albero, M.; Collado-Mataix, E. y Fuertes-Cabo, I. (2018): "Raw materials, gestures, objects. An approach to the work of bone and ivory in the Iron Age in the Iberian Peninsula", Quaternary International, 472, Part A, pp. 115125. https://doi.org/10.1016/j.quaint.2017.11.045

Mateos, C. M. a y SÁnchez, D. (2014): "El cuchillo afalcatado. Análisis tipológico y funcional de los cuchillos de los yacimientos abulenses durante la II Edad del Hierro". En González, F. J.; Paniagua, E. y De InÉs, P. (coords.): Investigaciones Arqueológicas en el valle del Duero, del Paleolítico a la Antigüedad Tardia. Actas III Jornadas de Jóvenes Investigadores del Valle del Duero. Salamanca: Glyphos Public., pp. 135-150.

Mederos, A. y Ruiz, L. A. (2004): "El pecio fenicio del Bajo Campana (Murcia, España) y el comercio del marfil norteafricano", Zephyrus, LVII, pp. 263-281.

Meillassoux, C. (1960): "Essai d'interpretación du phénomène économique dans les sociétés traditionnelles d'autosubsistance", Cahiers d'Études Africaines, 1 (4), pp. 38-67.

Molist, N. y Rovira, J. (1986-1989): "L'oppidum ausetà del Turó del Mongrós (El Brull, Osona)", Empúries, 48-50, pp. 122-141.

Monraval, M. (1992): La necrópolis ibérica de El Molar (San Fulgencio-Guardamar del Segura, Alicante). Catálogo de Fondos del Museo, v. Alicante.

Monraval, M. y López Piñol, M. (1984): "Restos de un silicernio en la necrópolis ibérica de El Molar", Saguntum, 18, pp. 145-162.

Murillo-Barroso, M.; Martínez, R. M. y Vera, J. C. (2018): "El ámbar de la cueva de los Cuarenta (Priego de Córdoba, Córdoba)", Trabajos de Prehistoria, 75 (2), pp. 333-343. doi.org/10.3989/tp.2018.12219

Naso, A. (2007): "Klinai lignee intarsiate dell Iona all'Europa central". En Mitteilungen des Deutschen Archäologischen Instituts Römische Abteilung, 113. Regensburg.

Olcina, M.; Grau, I.; Sala, F.; Moltó, S.; Reig, C. y Segura, J. M. (1998): "Nuevas aportaciones a la evolución de la ciudad ibérica: el ejemplo de La Serreta", Saguntum, Extra-1, pp. 34-46.

Negroni, N. (2011): "Amber and the Warrior Princes of the Orientalising Period in Italy". En Vianello, A. (ed.): Exotica in the Prehistoric Mediterranean. Oxford: Oxbow Books, pp. 63-95.

Olmos, R. (1987): "Posibles vasos de encargo en la cerámica ibérica del Sureste", Archivo Español de Arqueología, 60, pp. 21-42.

Page, V.; García Cano, J. M.; Iniesta, A. y Ruiz Sanz, M. ${ }^{\mathrm{a}}$ J. (1987): 10 años de excavaciones en Coimbra del Barranco Ancho. Jumilla. Murcia. 
Pallarés, F. (1965): El poblado ibérico de San Antonio de Calaceite. Monografías Prehistóricas y Arqueológicas, v. Barcelona: Instituto Internacional de Estudios Ligures.

Peña, A. (2003): La necrópolis ibérica de El Molar (San Fulgencio-Alicante). Revisión de las excavaciones realizadas en 1928 y 1929 . Villena.

Perea, A. (1990): "Estudio microscópico y microanalítico de las soldaduras y otros procesos técnicos en la orfebrería prehistórica del sur de la península ibérica”, Trabajos de Prehistoria, 47, pp. 103-160.

Pons, E. (dir.) (2002): Mas Castellar de Pontos (Alt Empordà). Un complex arqueològic d'època ibérica (excavacions 1990-1998). Sèrie Monogràfica, 21. Girona: MAC.

Prada, M. de y Cuadrado, E. (2019): La necrópolis ibérica de El Cigarralejo (Mula, Murcia). Segunda parte. Monografías del Museo de Arte Ibérico de El Cigarralejo. Murcia.

Quesada, F.; Gabaldón, M.; Requena, F. y Zamora, M. (2000): “'Artesanos itinerantes en el mundo ibérico? Sobre técnicas y estilos decorativos, especialistas y territorios", Saguntum, Extra-3, pp. 261-301.

Rafel, N.; Garcia-Rubert, D. y Jornet, R. (2015): Nuevos datos sobre el poblamiento en la Cataluña meridional entre el siglo VII ane y época romana: el Coll del Moro de Gandesa. Opúsculo Arqueológico, 9. Teruel: Seminario de Arqueología y Etnología Turolense.

Rodríguez Martín, F. G. (2014): “Artesanos y talleres del hueso en la Hispania Romana”. En Bustamante, M. y Bernal, D. (eds.): Artifices idóneos: Artesanos, talleres y manufacturas en Hispania. Madrid: csic, pp. 355-387.

Sahlins, M. (1983 [1974]): Economía de la Edad de Piedra. Madrid: Akal.

SANMARtí-Grego, E. (1975): "Las cerámicas finas de importación de los poblados prerromanos del Bajo Aragón (Comarca del Matarranya)", Cuadernos de Prehistoria y Arqueología Castellonense, 2, pp. 87-132.

Schummacher, T. X. y Banerjee, A. (2012): "Procedencia e intercambio de marfil en el Calcolítico de la Península Ibérica”, Rubricatum: Revista del Museu de Gavà, 5, pp. 289-298.

Sciutto, G.; Prati, S.; Bonacini, I.; Oliveri, P. y MaZZEO, R. (2014): "FT-NIR: An advanced spectroscopic approach for the characterisation of paint cross-sections", Microchemical Journal, 112, pp. 87-96. https://doi.org/10.1016/j.microc.2013.09.021

Senent, J. J. (1930): Excavaciones en la necrópolis del Molar. Memorias de la Junta Superior de Excavaciones y Antigüedades, 107. Madrid.

VIGIL, M. (1969): El vidrio en el mundo antiguo. Madrid. Vives-Ferrándiz, J. y Mata, C. (2020): "Iron metallurgy, political economy and social change during the first millennium BC in eastern Iberia”. En BELARTE, M. C.; Rovira, M. C. y Sanmartí, J. (eds.): Iron Metallurgy and the Formation of Complex Societies in the Western Mediterranean ( $1^{\text {st }}$ millennium BC). Proceedings of the $8^{\text {th }}$ International Meeting of Calafell, from $\sigma^{\text {th }}$ to $8^{\text {th }}$ October 2016. Arqueo Mediterrània, 15. Calafell, pp. 141-160. 